\title{
From spiral cleavage to bilateral symmetry: the developmental cell lineage of the annelid brain
}

\author{
Pavel Vopalensky ${ }^{1}$, Maria Antonietta Tosches ${ }^{1}$, Kaia Achim ${ }^{1}$, Mette Handberg-Thorsager ${ }^{1,2}$ and Detlev Arendt ${ }^{1 *}$ (D)
}

\begin{abstract}
Background: During early development, patterns of cell division-embryonic cleavage-accompany the gradual restriction of blastomeres to specific cell fates. In Spiralia, which include annelids, mollusks, and flatworms, "spiral cleavage" produces a highly stereotypic, spiral-like arrangement of blastomeres and swimming trochophore-type larvae with rotational (spiral) symmetry. However, starting at larval stages, spiralian larvae acquire elements of bilateral symmetry, before they metamorphose into fully bilateral juveniles. How this spiral-to-bilateral transition occurs is not known and is especially puzzling for the early differentiating brain and head sensory organs, which emerge directly from the spiral cleavage pattern. Here we present the developmental cell lineage of the Platynereis larval episphere.

Results: Live-imaging recordings from the zygote to the mid-trochophore stage ( $~ 30 \mathrm{hpf}$ ) of the larval episphere of the marine annelid Platynereis dumerilii reveal highly stereotypical development and an invariant cell lineage of early differentiating cell types. The larval brain and head sensory organs develop from 11 pairs of bilateral founders, each giving rise to identical clones on the right and left body sides. Relating the origin of each bilateral founder pair back to the spiral cleavage pattern, we uncover highly divergent origins: while some founder pairs originate from corresponding cells in the spiralian lineage on each body side, others originate from non-corresponding cells, and yet others derive from a single cell within one quadrant. Integrating lineage and gene expression data for several embryonic and larval stages, we find that the conserved head patterning genes otx and six 3 are expressed in bilateral founders representing divergent lineage histories and giving rise to early differentiating cholinergic neurons and head sensory organs, respectively.

Conclusions: We present the complete developmental cell lineage of the Platynereis larval episphere, and thus the first comprehensive account of the spiral-to-bilateral transition in a developing spiralian. The bilateral symmetry of the head emerges from pairs of bilateral founders, similar to the trunk; however, the head founders are more numerous and show striking left-right asymmetries in lineage behavior that we relate to differential gene expression.
\end{abstract}

Keywords: Cell lineage, Cleavage, Spiralian, Development, Bilateral, Symmetry

\section{Background}

During early development, embryonic cleavages produce blastomeres via a rapid series of cell divisions without significant growth, relying on maternally deposited messengers and proteins. During these divisions, the initially broad developmental potential of blastomeres becomes gradually restricted towards distinct cell fates. This can

\footnotetext{
*Correspondence: arendt@embl.de

'Developmental Biology Unit, European Molecular Biology Laboratory,

Meyerhofstraße 1, 69117 Heidelberg, Germany

Full list of author information is available at the end of the article
}

occur via two basic modes: (i) regulative (conditional) development, exhibited by cnidarians, sea urchins, and vertebrates [1], where almost all blastomeres share a broad developmental potential and cell fate determination largely depends on local signaling events, or (ii) mosaic development, where most blastomeres inherit distinct maternal determinants and signaling is assumed to play a minor role. Mosaic development is considered characteristic for the Spiralia, a large group of invertebrate phyla within the clade Lophotrohozoa [2, 3], but also for nematodes [4] and ascidians [5, 6]. It requires

(c) The Author(s). 2019 Open Access This article is distributed under the terms of the Creative Commons Attribution 4.0 International License (http://creativecommons.org/licenses/by/4.0/), which permits unrestricted use, distribution, and reproduction in any medium, provided you give appropriate credit to the original author(s) and the source, provide a link to the Creative Commons license, and indicate if changes were made. The Creative Commons Public Domain Dedication waiver (http://creativecommons.org/publicdomain/zero/1.0/) applies to the data made available in this article, unless otherwise stated. 
differential in ovo localization of determinants, a stereotypic arrangement of cleaving blastomeres and an invariant cell lineage. Recent results, however, hint at a considerable degree of cell-cell signaling also in these species with invariant lineages $[7,8]$, which underscores that regulative and mosaic development mostly differ in the relative contributions of autonomous versus conditional cell fate determination.

In Spiralia, the eponymous "spiral cleavage" produces a highly stereotypic, spiral-like arrangement of blastomeres (Fig. 1a) (reviewed in $[10,11])$ : The first two cleavages, perpendicular to each other, subdivide the embryo along the animal-vegetal axis into four blastomeres, representing the four future embryonic "quadrants" $\mathrm{A}, \mathrm{B}, \mathrm{C}$, and $\mathrm{D}$ [2]. The subsequent cleavages are asymmetrical, generating quartets of smaller micromeres towards the animal pole and quartets of bigger macromeres towards the vegetal pole. In addition, due to an oblique angle of these divisions, the originating micromere quartets are alternately turned clock- or counterclockwise against the macromere quartet, so that the micromeres come to be located in the furrows between the macromeres (Fig. 1a). The initial cleavage pattern is identical for each quadrant, so that the whole early embryo shows a fourfold rotational symmetry around the animal-vegetal axis. Corresponding cells with similar lineage in the four quadrants are here referred to as quadrant homologs.

In many annelids and mollusks, spiral cleavage produces spherical planctonic larvae called trochophore larvae (Fig. 1a). The larvae form a simple nervous system that integrates sensory information from photo-, mechano-, and chemosensory receptor cells for the control of ciliary locomotion [12-14]. Its most prominent features are an apical nervous system with an apical organ underlying an apical tuft. The apical organ is connected via radial nerves to a ring nerve $[10,11]$. The ring nerve innervates a pronounced circular ciliary band, the prototroch, subdividing the larva into an upper episphere and a lower hyposphere. During settlement metamorphosis, the larva transforms into an adult body with overt bilateral symmetry (or more or less complex derivatives thereof, see for instance the development of Crepidula [15, 16] and Ilyanassa [17]). The former episphere of the larva develops into the head including a prominent pair of cerebral ganglia. The hyposphere gives rise to
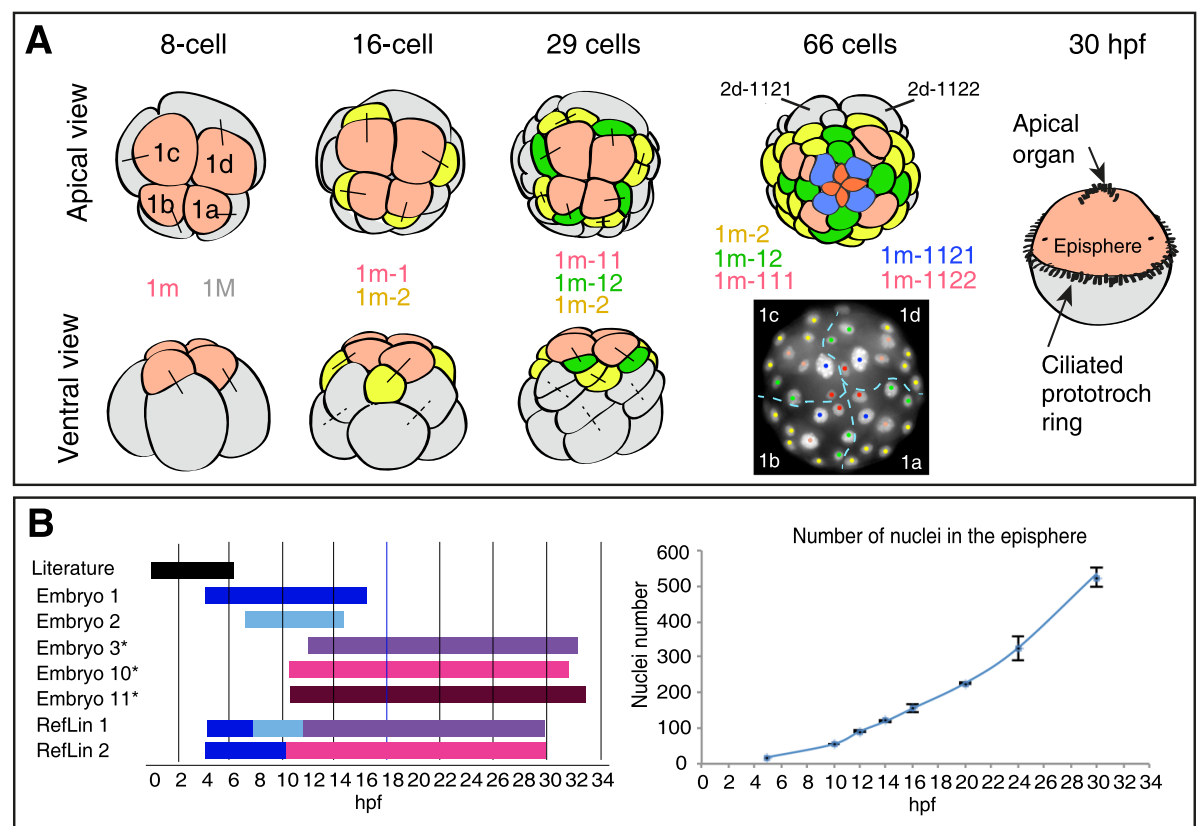

Fig. 1 Overview of early spiral cleavage and live imaging of the developing episphere. a The early development of a prototroch larva by spiral cleavage. The apical quartet of micromeres $1 \mathrm{~m}$ (light red) present at 8-cell stage gives rise to the episphere, whereas the quartet of macromeres $1 \mathrm{M}$ (gray) gives rise to the hyposphere. The precursors (1m-2) of the prototroch cells are labeled in yellow. For 66-cell stage, a schematic apical view (top) together with a corresponding snapshot (bottom) of the nuclear signal in the time-lapse recording of the developing episphere is shown. The colors of the nuclear tracks in the snapshot correspond to the coloring in the schematic apical view. The dashed blue line represents the border between embryonic quadrants. Apical views modified from [9]. The ventral views are extensively schematized for simplicity. b Lefthand panel shows the overview of time-lapse recordings used for the analysis of the cell lineage. Asterisks mark the movies used to create the consensus lineage tree (Additional file 10: Figure S2). The reference lineage movies RefLin1 (Additional file 3 and RefLin2 (Additional file 6) were assembled from 3 or 2 recordings, respectively, schematized by the colored bars along the timeline. To perform temporal calibration of the movie frames to developmental time, total nuclei in the episphere of at least three fixed specimens for each indicated stage $(5,10,12,14,16,20$, 24, and $30 \mathrm{hpf}$ ) were counted (plotted in the right-hand panel, error bars represent the standard deviation of the mean, $n=3$ ) 
the trunk including the paired ventral nerve cord $[10,11]$.

Hence, the most peculiar feature of spiralian development is the transition from the spiral (or rotational) symmetry to an overt bilateral symmetry, which has puzzled embryologists for more than a century (e.g., [18]). How is this spiral-to-bilateral transition accomplished? In the hyposphere, bilateral symmetry is established through the unique behavior of two cells, $2 \mathrm{~d}-112$ and $4 \mathrm{~d}$ [18], that divide once into the left and right bilateral founder cells of the entire trunk and give rise to trunk ectoderm and mesoderm, respectively [19-22]. The situation is more complicated in the episphere, where the bilateral symmetry has to emerge from a pre-existing pattern of spirally arranged micromeres. Here, the spiral-to-bilateral transition may involve a "rearrangement" of micromere position via complex cellular movements, or start from selected bilateral founders-thus analogous to the trunk founders. The latter solution was favored by E. B. Wilson [18], who gave an early and detailed account of spiral cleavage in the annelid Nereis. After the appearance of the prototroch, he observed a sudden transition from spiral to bilateral cleavage pattern that he attributed to a pair of (yet to be identified) bilateral founders.

Previous studies in Platynereis and other spiralians had established the bilateral fate of early micromeres by injection of tracer dyes, yet did not resolve their lineage in cellular resolution $[15,23,24]$. To understand how bilateral symmetry is established, we reconstructed the full developmental cell lineage for the episphere (apical hemisphere) of the marine annelid Platynereis dumerilii from the fertilized egg to the swimming trochophore stage at $\sim 30 \mathrm{~h}$ post fertilization (hpf). In addition, we linked early lineages to gene expression using a cellular resolution gene expression atlas for several embryonic stages (compare to [25]). This resource is extended here to the episphere undergoing spiral-to-bilateral transition. The time-lapse recordings, software tools, and lineage analysis presented here generate an unprecedented resource for spiralian biology available so far only for nematode and tunicate model systems.

Our lineage analysis allows tracking the spiral-tobilateral transition in cellular detail. As postulated by Wilson, we identify bilateral founder cells; yet, we observe an extensive array of paired bilateral founders distributed over the entire episphere at around $12 \mathrm{hpf}$. Some of them, located in the lateral episphere represent quadrant homologs, that is, they stem from similar (i.e., corresponding) lineages in their respective quadrants. Others, located more medially, stem from dissimilar lineages in their respective quadrants. Mapping the expression of the conserved bilaterian head patterning genes otx and six3 to the developmental lineage, we find that lateral otx expression marks the bilateral founders with similar lineage, whereas medial six 3 marks those of dissimilar lineage. Moreover, we find that while the $o t x+$ lateral founders show strong proliferation during larval stages and remain mostly undifferentiated at $30 \mathrm{hpf}$, the six3+ medial founders differentiate earlier and give rise, among others, to bilateral pairs of cholinergic neurons in the larval brain. Finally, we find that the apical organ proper does not develop from bilateral founders, but originates from the most medial cells that lack bilateral symmetry.

We relate our findings to the fast succession of two fundamentally distinct phases of spiralian development in Platynereis: an early embryonic phase with mosaic and determinate elements, giving rise to rotationally symmetrical cell types of the larval body such as the ciliated prototroch, and a later regulative phase characterized by positional specification of the bilateral founders on each side of the developing head. These two phases appear universally present in the spiralian life cycle.

\section{Results \\ Live imaging and tracking of the cell lineage in the Platynereis episphere}

The annelid head (the brain and associated sensory organs) is almost entirely formed by the offspring of the apical micromeres $1 \mathrm{a}, 1 \mathrm{~b}, 1 \mathrm{c}$, and $1 \mathrm{~d}$, here collectively referred to as " $1 \mathrm{~m}$ " $[23,26]$. The development of the $1 \mathrm{~m}$ micromeres is easily accessible to live imaging by standard laser scanning confocal microscopy. To track cell divisions in the developing head, we injected embryos at different stages post fertilization $(1,2$, or 4 cell stage) with $h 2 a-r f p$ and lyn-egfp mRNAs [27], which label chromatin and cell membranes, respectively. Then we recorded time-lapse movies of these apically mounted embryos (Fig. 1a, b, and 4D recordings of each embryo available in online data repository [28]). To track and reconstruct the lineage, we developed a package of simple macros for ImageJ/FIJI [29] allowing manual tracking and visualization of lineage-related information from confocal microscopy stacks (Additional files 1 and 2). We tracked all cell divisions in the episphere of multiple embryos spanning the developmental time from 16-cell stage ( $\sim 2 \mathrm{hpf})$ until $\sim 32 \mathrm{hpf}$ when more than 500 cells are present in the episphere (Fig. 1b), with at least three embryos coverage per developmental stage (original 4D recordings of each embryo available in online data repository [28]), Z-projections combined in reference lineage movies are provided in Additional files 3, 4, 5, 6, 7 , and 8 . This comprehensive dataset allowed us to perform detailed cell lineage analyses of developmental stereotypicality, clonal behavior, and the transition from spiral to bilateral symmetry. 
The cell divisions follow a stereotypical pattern in the Platynereis episphere until swimming larval stages To investigate the reproducibility of cell division patterns across individuals, we injected nuclear tracers into 2- and 4-cell stage embryos and compared the resulting clonal domains with the results of the live imaging at 32 hpf. The clonal domains originating from tracer dye injections were in a good agreement with the shape and position of the clonal domains inferred from the tracked time-lapse movies (Additional file 9: Figure S1A-D'), pointing to a high level of stereotypicality. In addition, the shape and overall arrangement of the clonal domains originating from $\sim 13 \mathrm{hpf}$ are highly similar between embryos (Additional file 9: Figure S1E). To address the stereotypicality of episphere development beyond this time point, we identified corresponding cells in different imaged specimens on the basis of lineage information, relative cell positions at division, and cell cycle length (Additional file 9: Figure S1F-H, see the "Materials and methods" section for more details). We compared the time-lapse movies of more than three independent (injections at different days) specimens up to $24 \mathrm{hpf}$ and three specimens until $30 \mathrm{hpf}$ (Fig. 1b). The embryos showed no differences until $16 \mathrm{hpf}$. Afterwards, the embryos showed a largely stereotypical development, both at the level of the lineage tree topology as well as cell positions, with only a small number of differences distributed over the developing episphere (Fig. 2a-c). These differences could be attributed either to biological variance or to minor late developmental aberrations due to cumulative phototoxicity. The only exception is the ventral apical rosette cell 1b-111, which shows most variability in timing and division pattern observed across larvae (see below). Based on the analyzed embryos and available literature, we generated a consensus lineage tree of the episphere from the egg until $30 \mathrm{hpf}$ and annotated the identified cell types (Fig. 2d and Additional files 10: Figure S2 and 11: Table S1). Taken together, our comparative analysis shows that Platynereis brain development is highly stereotypical at the level of overall cell arrangement and lineage tree topology.

\section{Early differentiating cells show an invariant cell lineage}

To date, the only differentiated cells for which the cell lineage has been fully described in Platynereis episphere are the primary prototroch cells [26]. In our time-lapse recordings, several differentiated cell types could be directly identified based on their morphology and other microscopical features: the prototroch cells, the larval eye pigment cells, the five ventral gland cells (Fig. 3A), and several cell types in the apical organ (Fig. 3B) [14]. In addition to morphological and anatomical identification, we also mapped the expression of the cholinergic marker Choline Acetyl Transferase (chat) on the lineage, by performing whole-mount mRNA in situ hybridization (WMISH) on live-imaged and lineage-tracked embryos fixed just after the last timeframe of the recording (Fig. 3C). At $30 \mathrm{hpf}$, the chat expression pattern comprises nine differentiated cells, mostly involved in controlling cilio-motor behavior $[12,13,30]$. Another hallmark of differentiating neurons is the formation of axons. Zygotic injection of the nuclear marker $h 2 a-r f p$ mRNA followed by the injection of lifeAct-EGFP mRNA (labeling actin filaments) into a single blastomere at 2cell or 4-cell stage allows following the lineage of cells forming axonal projections (Fig. 3D-E'). With this approach, we identified two apical cells projecting outside the $\mathrm{AB}$ domain (Fig. 3D-D") and cells with axons traversing the dorso-ventral midline (Fig. 3E, E'). We also observed several apoptotic cells characterized by condensation and later dissociation of nuclear content, showing the same lineage in all investigated embryos (Fig. 3F). In addition, to link cellular lineages to differential gene expression, we conducted WMISH expression analysis for markers for cholinergic neurons-choline acetyltransferase (chat), for neuropeptidergic neuronsprohormone convertase 2 ( $p h c 2$ ), and for glutamatergic neurons-vesicular glutamate transporter (vglut) (Fig. 3F and Additional file 12: Figure S3). In total, we addressed the cell lineages of 62 non-dividing, presumably differentiated cell types in the $30 \mathrm{hpf}$ episphere, summarized in (Fig. 3F and Table 1).

Because the stereotypic tree topology and cell positions suggest an invariant cell lineage, the same cell types should be produced by the same cell lineage in different embryos. Indeed, for the vast majority of cell types with the last cell division observed before $\sim 15 \mathrm{hpf}$, the cell lineage is strictly conserved among multiple embryos (column "Support" in Table 1). Interestingly, the cell lineage varies in later-born cells, e.g., chat + cell r1125/ r1121 (no. 52 in Table 1) exiting the cell cycle at $\sim 28$ hpf and cell r525 (no. 49 in Table 1) exiting at $\sim 20$ hpf. In summary, our analyses show that the Platynereis larval brain develops via stereotypical cell divisions and that the lineage of early differentiating neuronal cell types is highly reproducible between specimens.

\section{A gene expression atlas for embryonic and early larval stages} Next, we linked cellular lineages to gene expression, to gain insights into the potential role of apical transcription factors and the identity of differentiating cell types. For this, we generated a whole-mount in situ hybridization (WMISH) atlas with a total of 23 genes for 7 stages $(12,14,16,20,24,30$, and $34 \mathrm{hpf}$ ) (Additional files 12: Figure S3 and 13: Table S2). Since most of the identified early differentiating larval cells represent neural cell types, we included neural regionalization and specification transcription factors from the homeodomain, basic helix-loop-helix (bHLH) and zinc 

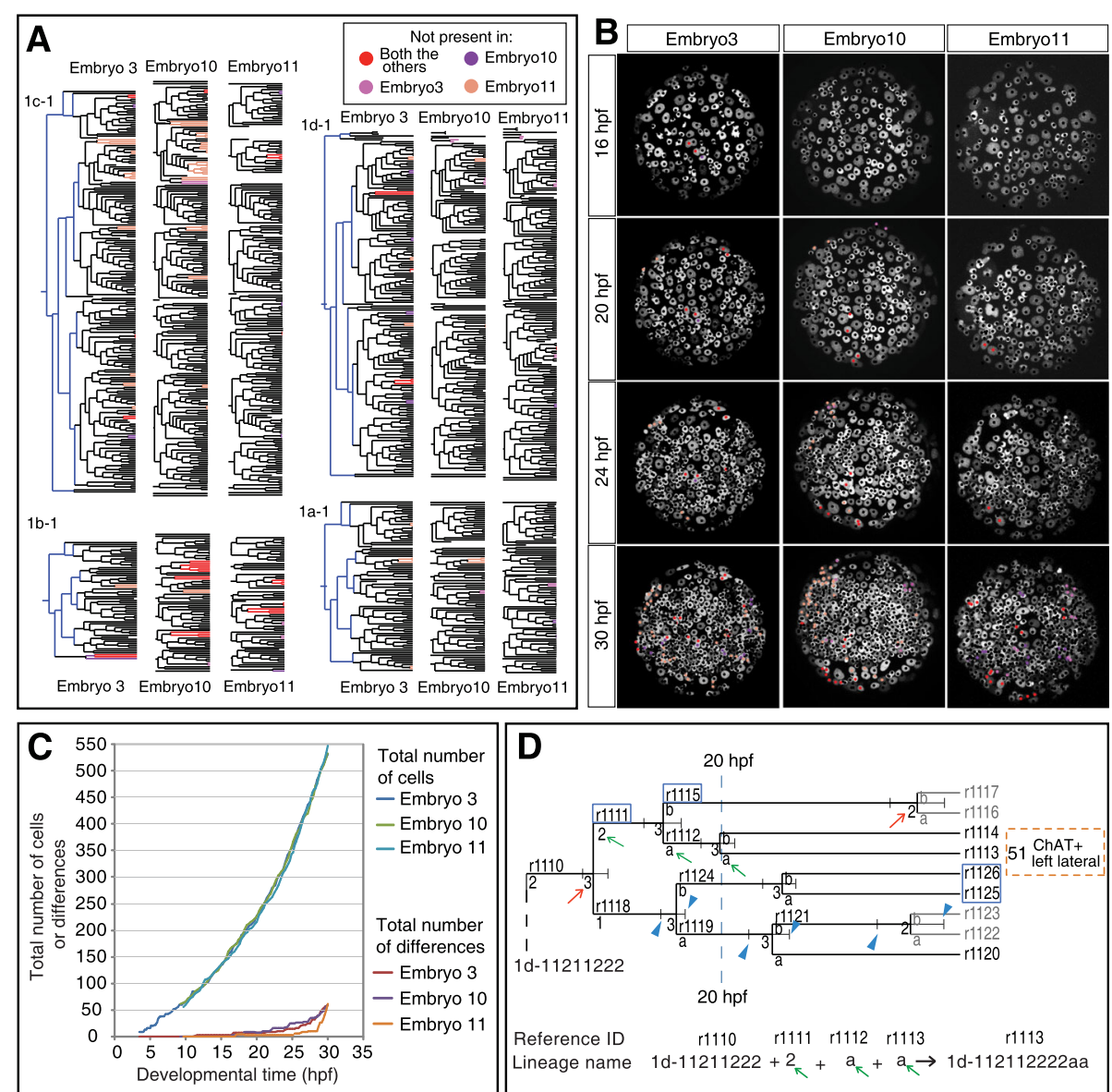

Fig. 2 The stereotypicality of episphere development. a The comparison of the cell lineage trees of three larvae at 30 hpf. Blue branches in the lineage trees of embryo 3 represent the early developmental lineage (0-6 hpf) described in previous study [23], but not captured by the liveimaging movies in this work. Corresponding cells/divisions conserved in all three larvae are colored in black. The divisions and cells that do not occur in all three larvae are color-coded according to the legend. $\mathbf{b}$ The snapshots of the Z-projection of the live-imaging movies showing the differences between the three larvae at different time points. Differences are color-coded as in panel a. c Quantification of differences among embryos. The total number of differences represents the number of cells that are not present in the other two embryos at a given time point. The differences start to appear around $16 \mathrm{hpf}$ and increase with time, reaching around $10 \%$ of the total cell number in the episphere at 30 hpf. $\mathbf{d}$ A cut-out from the consensus lineage tree (Additional file 10: Figure S2) illustrating the annotation system: The reference IDs (examples in blue boxes) are unique identifiers of each cell throughout the lineage tree and track files. Each division produces two daughter cells, whose lineage name is extended by a "1" (or "a") or "2" (or "b"). The letter of extension is given at the edge connecting the vertical line (representing the division point) and the horizontal branch (green arrows). Using this system, the full lineage name can be read out from the consensus lineage tree. The red arrow at the division point indicates the number of embryos in which the given division occurred (max. 3). If the division occurred in only 2 out of 3 embryos, the subsequent branch lines are shaded in gray, instead of black color

finger family (Additional file 12: Figure S3A-B) and general neural differentiation markers (Additional file 12: Figure S3C).

Using our collection, we found that the transcription factors coe, ngn, neuroD, and prox are co-expressed with the neuronal differentiation markers elav and syt, the cholinergic marker chat, and the neuropeptidergic marker $p h c 2$ in the apical organ cells (no. 46 and no. 53, later serotonergic, in Table 1). At later stages, even when expressing cells could no longer be identified individually, our analysis revealed expression correlations and transcriptional dynamics in neural lineages. For example, the expression of the neuronal specification factors prox, $n g n$, and neuroD appears to always faithfully anticipate expression of the pan-neuronal marker elav (compare Additional file 12: Figure S3A-C). Similarly, we observed that expression of the bHLH factor coe precedes the expression of cholinergic markers vacht and chat several hours later (compare Additional file 12: Figure S3, panels $\mathrm{A}$ and $\mathrm{C}$ ), in line with the evolutionary conserved role of COE factors in specification of cholinergic neurons [31]. Interestingly, the expression of the two neuronal differentiation markers $p h c 2$ and $s y t$ remains restricted to the apical organ region between 24 and $34 \mathrm{hpf}$, partially 

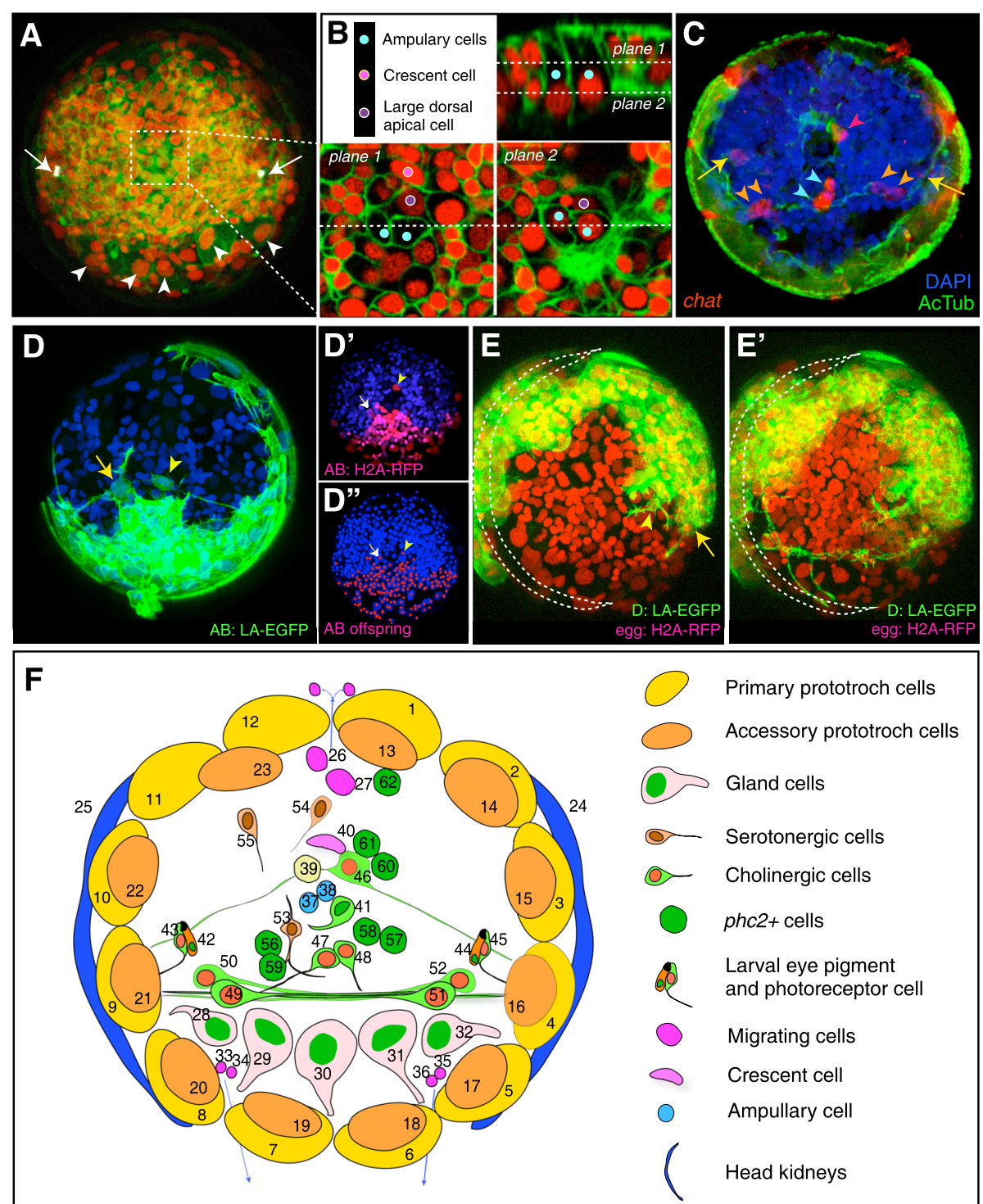

Fig. 3 Differentiated cell types with known lineage at $30 \mathrm{hpf}$. A, B Cell types identified directly in the last frame of the time-lapse recordings by their position and morphological features. The larval eye pigment cells identified by their autofluorescence in the red spectrum (A, white arrows). The large gland cells with the typical flask shape and large size (A, white arrowheads). B Several cell types of the apical organ could be identified by their morphology and position (described in detail in [14]). $\mathbf{C}$ The WMISH of chat performed on the live-imaged larva (shown in panel $\mathbf{A}$ ) fixed immediately after imaging allows addressing the cell lineages of cholinergic neurons. Yellow arrows indicate the position of larval eye photoreceptors, orange arrowheads the ventrolateral ChAT+ cells, red arrowhead the apical ChAT+ cells with first lateral axons, and blue arrowheads the ventromedial cholinergic cells. D Two apical neurons with axons revealed by injection of the AB blastomere with la-egfp mRNA. The neuron with the ventrolateral projections lies outside from the rest of the AB-labeled domain $\left(\mathbf{D}^{\prime}\right.$ and $\left.\mathbf{D}^{\prime \prime}\right)$. E, $\mathbf{E}^{\prime}$ The snapshots of a time-lapse recording of larvae injected with $h 2 a-$ rfpmRNA at 1-cell stage and la-egfp to the D blastomere shows the axon of a flask-shaped cell in the apical organ (yellow arrowhead) and the growing axon of the ventral cholinergic cells (yellow arrow). The prototroch ring is indicated by a dashed crescent. $\mathbf{F}$ A summary diagram of the differentiated cell types in the episphere at $\sim 30 \mathrm{hpf}$. The numbering corresponds to the first column of Table 1

overlapping with the cholinergic markers chat and vacht. This suggests that cholinergic and neurosecretory cells form the core of the larval apical nervous system, in line with single-cell RNA sequencing results [32]. The restricted and stable expression of $p h c 2$ and the cholinergic markers contrasts with the rather dynamic expression of neuroD, ngn, and elav that demarcate neuronal specification more broadly in the developing cerebral ganglia.

\section{Lineages not transitioning to bilateral symmetry}

The Platynereis cell lineage tree and the gene expression atlas can be used to analyze the symmetry properties of individual cell lineages, in combination with gene expression, 
Table 1 The cell lineage of the differentiated cell types at $30 \mathrm{hpf}$

\begin{tabular}{|c|c|c|c|c|c|}
\hline No. & Cell type & Lineage & Support & Last observed division & $\mathrm{rID}$ \\
\hline 1 & Posterior prototroch 1 & $1 d-221$ & Refs. $+(2 / 2)$ & $\sim 7 \mathrm{hpf}$ & $r 1365$ \\
\hline 2 & Posterior prototroch 2 & $1 d-222$ & Refs. $+(2 / 2)$ & $\sim 7 \mathrm{hpf}$ & r1366 \\
\hline 3 & Posterior prototroch 3 & $1 d-212$ & Refs. $+(2 / 2)$ & $\sim 6.5 \mathrm{hpf}$ & r1363 \\
\hline 4 & Posterior prototroch 4 & $1 a-221$ & Refs. $+(2 / 2)$ & $\sim 7 \mathrm{hpf}$ & $\mathrm{r} 215$ \\
\hline 5 & Posterior prototroch 5 & $1 a-222$ & Refs. $+(2 / 2)$ & $\sim 7 \mathrm{hpf}$ & $\mathrm{r} 216$ \\
\hline 6 & Posterior prototroch 6 & $1 a-212$ & Refs. $+(2 / 2)$ & $\sim 7 \mathrm{hpf}$ & r213 \\
\hline 7 & Posterior prototroch 7 & $1 b-221$ & Refs. $+(2 / 2)$ & $\sim 7 \mathrm{hpf}$ & r361 \\
\hline 8 & Posterior prototroch 8 & $1 b-222$ & Refs. $+(2 / 2)$ & $\sim 7 \mathrm{hpf}$ & r362 \\
\hline 9 & Posterior prototroch 9 & $1 b-212$ & Refs. $+(2 / 2)$ & $\sim 7 \mathrm{hpf}$ & r359 \\
\hline 10 & Posterior prototroch 10 & $1 c-221$ & Refs. $+(2 / 2)$ & $\sim 7 \mathrm{hpf}$ & r899 \\
\hline 11 & Posterior prototroch 11 & $1 c-222$ & Refs. $+(2 / 2)$ & $\sim 7 \mathrm{hpf}$ & r900 \\
\hline 12 & Posterior prototroch 12 & $1 c-212$ & Refs. $+(2 / 2)$ & $\sim 7 \mathrm{hpf}$ & r897 \\
\hline 13 & Anterior prototroch 1 & $1 d-1221$ & $(3 / 3)$ & $\sim 8.5 \mathrm{hpf}$ & r1356 \\
\hline 14 & Anterior prototroch 2 & $1 d-211$ & Refs. $+(2 / 2)$ & $\sim 6.5 \mathrm{hpf}$ & r1362 \\
\hline 15 & Anterior prototroch 3 & $1 a-1212$ & $(3 / 3)$ & $\sim 8.5 \mathrm{hpf}$ & r208 \\
\hline 16 & Anterior prototroch 4 & $1 a-122$ & $(3 / 3)$ & $\sim 7 \mathrm{hpf}$ & r209 \\
\hline 17 & Anterior prototroch 5 & $1 a-211$ & Refs. $+(2 / 2)$ & $\sim 7 \mathrm{hpf}$ & r212 \\
\hline 18 & Anterior prototroch 6 & $1 b-1212$ & $(3 / 3)$ & $\sim 8.5 \mathrm{hpf}$ & r354 \\
\hline 19 & Anterior prototroch 7 & $1 b-122$ & $(3 / 3)$ & $\sim 7 \mathrm{hpf}$ & r355 \\
\hline 20 & Anterior prototroch 8 & $1 b-211$ & Refs. $+(2 / 2)$ & $\sim 7 \mathrm{hpf}$ & r358 \\
\hline 21 & Anterior prototroch 9 & $1 c-1212$ & $(3 / 3)$ & $\sim 8.5 \mathrm{hpf}$ & r892 \\
\hline 22 & Anterior prototroch 10 & $1 c-122$ & $(3 / 3)$ & $\sim 7 \mathrm{hpf}$ & r893 \\
\hline 23 & Anterior prototroch 11-12 & $1 c-211$ & Refs. $+(2 / 2)$ & $\sim 7 \mathrm{hpf}$ & r896 \\
\hline 24 & Left head kidney & $1 d-11,221$ & $(5 / 5)$ & $\sim 7 \mathrm{hpf}$ & $r 1133$ \\
\hline 25 & Right head kidney & $1 c-11221$ & $(5 / 5)$ & $\sim 7 \mathrm{hpf}$ & r613 \\
\hline 26 & Dorsally migrating $1^{\text {st }}$ wave & $1 d-1222$ & $(5 / 5)$ & $\sim 8.5 \mathrm{hpf}$ & r1357 \\
\hline 27 & Dorsally migrating $2^{\text {nd }}$ wave & $1 d-121$ & $(5 / 5)$ & $\sim 7 \mathrm{hpf}$ & r1352 \\
\hline 28 & Gland most right (GRR) & $1 b-112211121$ & $(3 / 4)$ & $\sim 15.5 \mathrm{hpf}$ & $r 267$ \\
\hline 29 & Gland middle right (GMR) & $1 b-11221222$ & $(3 / 3)$ & $\sim 13.5 \mathrm{hpf}$ & $\mathrm{r} 295$ \\
\hline 30 & Gland middle (GMM) & $1 b-121122$ & $(3 / 3)$ & $\sim 13 \mathrm{hpf}$ & r353 \\
\hline 31 & Gland middle left (GML) & $1 a-11221222$ & $(3 / 3)$ & $\sim 13.5 \mathrm{hpf}$ & $r 126$ \\
\hline 32 & Gland most left (GLL) & $1 a-112211121$ & $(3 / 3)$ & $\sim 15.5 \mathrm{hpf}$ & $r 118$ \\
\hline 33 & Apoptotic upper right & $1 c-12111$ & $(3 / 3)$ & $\sim 10.5 \mathrm{hpf}$ & r838 \\
\hline 34 & Apoptotic lower right & $1 b-1122112$ & $(3 / 3)$ & $\sim 11 \mathrm{hpf}$ & $\mathrm{r} 290$ \\
\hline 35 & Apoptotic upper left & $1 a-12111$ & $(3 / 3)$ & $\sim 10.5 \mathrm{hpf}$ & r158 \\
\hline 36 & Apoptotic lower left & $1 a-1122112$ & $(3 / 3)$ & $\sim 11 \mathrm{hpf}$ & $r 122$ \\
\hline 37 & Ampullary cell right & 1c-1112 & $(3 / 3)$ & $\sim 9 \mathrm{hpf}$ & r367 \\
\hline 38 & Ampullary cell left & $1 c-1111$ & $(3 / 3)$ & $\sim 9 \mathrm{hpf}$ & r366 \\
\hline 39 & Large dorsal apical cell & $1 d-1112$ & $(5 / 5)$ & $\sim 10 \mathrm{hpf}$ & r905 \\
\hline 40 & Crescent cell & 1c-112121222 & $(4 / 4)$ & $\sim 17.5 \mathrm{hpf}$ & $r 574$ \\
\hline 41 & First axon apical organ & $1 d-1111$ & $(3 / 3)$ & $\sim 10 \mathrm{hpf}$ & r904 \\
\hline 42 & Larval eye pigment cell right & $1 c-121121 b$ & $(3 / 3)$ & $\sim 16 \mathrm{hpf}$ & r842 \\
\hline 43 & Larval eye photoreceptor right, chat+ & $1 c-121121 a$ & $(3 / 3)$ & $\sim 16 \mathrm{hpf}$ & r841 \\
\hline 44 & Larval eye pigment cell left & $1 a-1211211$ & $(3 / 3)$ & $\sim 16 \mathrm{hpf}$ & r206 \\
\hline
\end{tabular}


Table 1 The cell lineage of the differentiated cell types at 30 hpf (Continued)

\begin{tabular}{|c|c|c|c|c|c|}
\hline No. & Cell type & Lineage & Support & Last observed division & $\mathrm{rID}$ \\
\hline 45 & Larval eye photoreceptor left, chat+ & $1 a-1211212$ & $(3 / 3)$ & $\sim 16 \mathrm{hpf}$ & r207 \\
\hline 46 & chat+ apical dorsal, phc2+, first bilateral axons & $1 a-11111$ & $(3 / 3)$ & $\sim 11.5 \mathrm{hpf}$ & r5 \\
\hline 47 & chat+ apical ventral peripheral (AVP) & $1 a-11212112 b$ & $(3 / 3)$ & $\sim 16.5 \mathrm{hpf}$ & r86 \\
\hline 48 & chat+ apical ventral medial (AVM) & $1 a-11211212 b$ & $(3 / 3)$ & $\sim 18 \mathrm{hpf}$ & r50 \\
\hline 49 & chat+ right lateral bigger (RLP) & $1 \mathrm{c}-112112222 \mathrm{ba}$ & $(4 / 5)$ & $\sim 20 \mathrm{hpf}$ & r525 \\
\hline 50 & chat+ right lateral ventral (RLV) & $1 b-11211221$ & $(3 / 4)$ & $\sim 16.5 \mathrm{hpf}$ & r241 \\
\hline 51 & chat+ left lateral bigger (LLP) & 1d-112112222аa & $(3 / 3)$ & $\sim 20 \mathrm{hpf}$ & r1113 \\
\hline 52 & chat+ left lateral ventral (LLV) & $1 d-112112221 n n$ & $(2 / 2)$ & $\sim 28 / \sim 29 \mathrm{hpf}$ & r1125/r1121 \\
\hline 53 & The right apical cell with axon, $5 H T+$, phc2+ & $1 b-1121111$ & $(1 / 1)$ & $\sim 14.8 \mathrm{hpf}$ & r226 \\
\hline 54 & The most dorsal serotonergic, $5 H T+$ & $1 c-112122122 a$ & $(1 / 1)$ & $\sim 17.5 \mathrm{hpf}$ & r583 \\
\hline 55 & Asymmetricserotonergic, $5 \mathrm{HT}+$ & $1 c-112222211 b b$ & $(1 / 1)$ & $\sim 22 \mathrm{hpf}$ & r834 \\
\hline 56 & phc2+ close to the right apical cell with axon, more dorsal & $1 b-1121112$ & $(1 / 1)$ & $\sim 14.8 \mathrm{hpf}$ & r227 \\
\hline 57 & phc2+ & $1 a-1122121$ & $(1 / 1)$ & $\sim 11.5 \mathrm{hpf}$ & $r 124$ \\
\hline 58 & phc2+ & $1 a-11112 b$ & $(1 / 1)$ & $\sim 15.6 \mathrm{hpf}$ & $r 24$ \\
\hline 59 & phc2+, close to the right apical cell with axon, more ventral & $1 b-1122121$ & $(1 / 1)$ & $\sim 11.5 \mathrm{hpf}$ & r292 \\
\hline 60 & phc $2+$ close to the crescent cell, more ventral & $1 d-112121$ & $(1 / 1)$ & $\sim 10 \mathrm{hpf}$ & r1128 \\
\hline 61 & phc2+ close to the crescent cell, more dorsal & $1 d-1121221$ & $(1 / 1)$ & $\sim 15.2 \mathrm{hpf}$ & r1130 \\
\hline 62 & Dorsal medial phc2+ & $1 d-1121222$ & $(1 / 1)$ & $\sim 15.2 \mathrm{hpf}$ & r1131 \\
\hline
\end{tabular}

The numbers in the first column correspond to the numbering in Fig. 3F. The column "Lineage" contains the consensus lineage name based on the literature and multiple time-lapse recordings. The "Support" column indicates the number of time-lapse recordings with the given cell lineage/the number of total time-lapse recordings analyzed for a given cell type. "Refs" indicates additional support from published literature [23]. The column "Last observed division" refers to the time point at which the last cell division was observed. Since most of the cells in this table show terminal differentiation characteristics, we consider the time of the last observed division being identical to cell cycle exit. The "rID" column contains the reference ID of the given cell type which corresponds to the rID in the tracking files (Additional files 4 and 7 and the tracking files of individual embryos provided in online data repository [28]) and the consensus lineage tree (Additional file 10: Figure S2)

cell type, and cell differentiation. We first focused on lineages that retained the initial rotational symmetry, or gave rise to unpaired, non-bilateral descendants along the axis of symmetry. In Platynereis, these lineages give rise to early differentiating cells of the prototroch, apical organ, and apical neurosecretory cells (Fig. 4).

The primary prototroch develops from the two vegetal-most quartets of the first micromeres, that is, $1 \mathrm{~m}-22$ and $1 \mathrm{~m}-21$, in a strictly radial arrangement (Fig. 4a, b). The blastomeres $1 \mathrm{~m}-12$, located slightly more apically, divide twice in a spiral mode (with an exception of 1d-12, see below) (Fig. 4b). They produce the non-dividing accessory prototroch cells $1 \mathrm{~m}-122$ and $1 \mathrm{~m}$ 1212. The primary prototroch cells form a rotationally symmetric, almost closed ring around the larval episphere. This ring forms a barrier between the episphere and hyposphere, only allowing cells to pass through a small "gap" between 1c-212 and 1d-221. We observed that episphere cells from the lineages $1 \mathrm{~d}-12$ and $1 \mathrm{c}-112$ migrate down to the hyposphere through this small passage (visible in Figs. 3F and 4b).

The apical organ develops from the four cells $1 \mathrm{~m}-111$ that form a prominent "apical rosette" in early development, characteristic for the spiral cleavage pattern [26] (Fig. 4a). These cells produce the early differentiating cells of the apical organ (Fig. 4c) that, together with the prototroch cells, form the first neuromotor circuit. A single division of $1 \mathrm{c}-111$ produces the two ampullary cells described previously [14]. The two daughters of 1d111 form the "large dorsal apical cell" and one of the flask-shaped cells of the apical organ [33]. The cell 1a111 buds off the cell 1a-1112 of unknown identity at around 9 hpf. The second daughter cell (1a-1111) divides at around $12 \mathrm{hpf}$ to give rise to the first ChATpositive cell (1a-11111). Its sister cell (1a-11112) divides multiple times, eventually producing a clone with bilateral symmetry to the clone descendant from 1b-112121 (purple clones in Fig. 5G), providing an example of bilateral clones not related by lineage (see below). The ventral rosette cell $1 \mathrm{~b}-111$ shows variable behavior among embryos, from no division (3/6 observed embryos) to one division ( $2 / 6$ embryos) or more divisions $(1 / 6 \mathrm{em}$ bryos). The timing of the first division of $1 \mathrm{~b}-111$ ranges from $\sim 12$ to $\sim 24 \mathrm{hpf}$. The large nuclear volume and rather low nuclear marker signal resemble the highly proliferative blast cells and suggest a possible proliferation in later development.

The apical neurosecretory cells develop from the $1 \mathrm{~m}$ 112 cells, which mostly give rise to bilateral clones (see below), but also produce a small set of descendants 

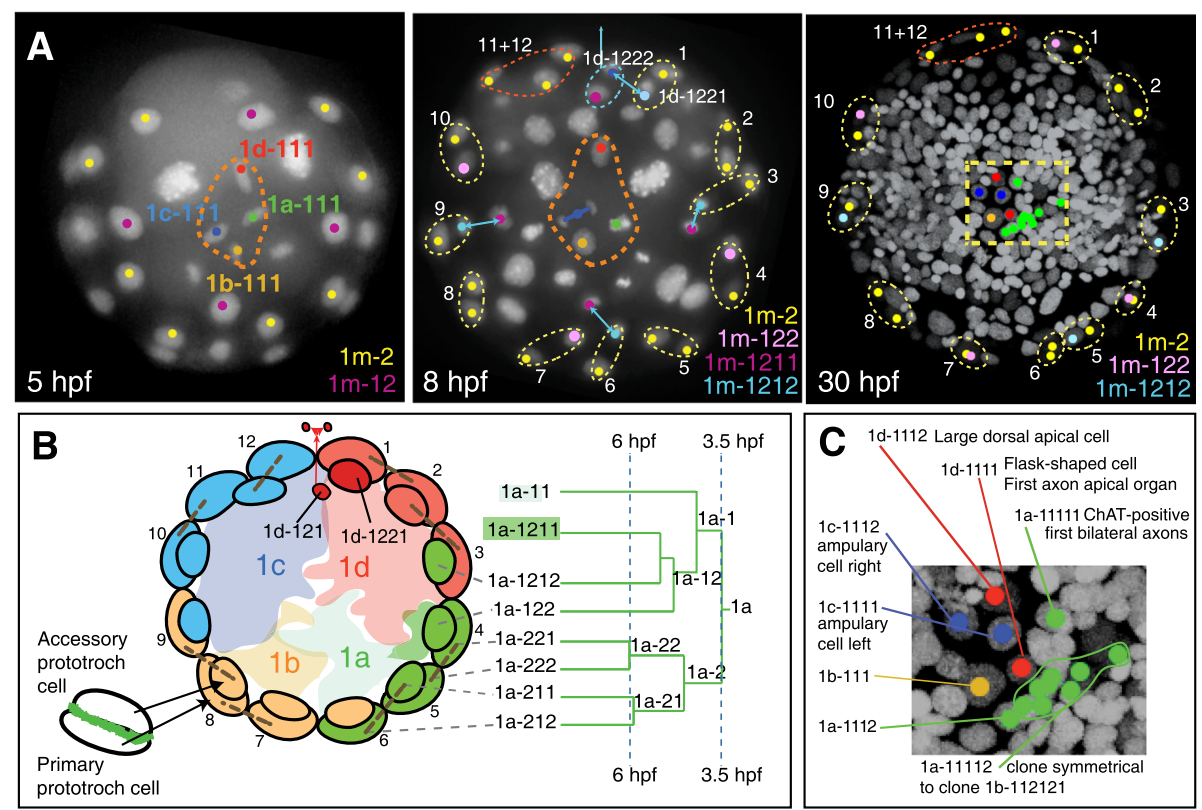

Fig. 4 The developmental origin of the accessory prototroch cells and the cells in the apical organ. a The overview of the development of the apical rosette (1m-111, orange dashed line) and the primary ( $1 \mathrm{~m}-2$, yellow) and accessory (1m-12, pink) prototroch cells at 5, 8, and 30 hpf. $\mathbf{b}$ Schematic diagram showing the lineage origin of the prototroch cells. Only the 1a quadrant lineage tree is shown here for simplicity. The cells in the scheme are color-coded by their quadrant of origin. The black dashed lines indicate sister cells. Each quadrant contributes three primary prototroch cells $(1 \mathrm{~m}-221,1 \mathrm{~m}-222,1 \mathrm{~m}-212)$ and three accessory prototroch cells $(1 \mathrm{~m}-211$-a sister cell of one of the primary prototroch cells, $1 \mathrm{~m}$ 1212 and $1 \mathrm{~m}$-122). The only exception is the $1 \mathrm{~d}$ quadrant producing only two accessory prototroch cells, due to the migration of the $1 \mathrm{~d}-121$ clone out of the episphere (see main text for details). Note that the triplet of the accessory prototroch cells originating from a given quadrant does not associate with the triplet of the primary prototroch cells of the same quadrant, but is rotated by one cell counter-clockwise. c A detailed scheme of the lineage origin of the apical organ cells

located along the dorsal midline and surrounding the apical organ (Fig. 3F and Table 1). These cells exit their last division before $15 \mathrm{hpf}$ and differentiate as neurosecretory cells expressing the neuropeptidergic marker phc2 (Table 1).

In summary, our analysis reveals that the prototroch, consisting mostly of cells exiting the cell cycle at $\sim 6 \mathrm{hpf}$, completely retains the rotational symmetry of the spiral cleavage pattern. The medially positioned cells of the apical organ and the medial neurosecretory cells do not show any signs of rotational or bilateral symmetry.

\section{An array of paired bilateral founder cells}

We next determined whether the bilaterally symmetrical Platynereis brain and head sensory organs would develop from bilateral founder cells, as do the ventral nerve cord and the trunk mesoderm that develop from the left and right descendants of the $2 \mathrm{~d}-221$ and $4 \mathrm{~d}$, respectively [18-22]. We defined "bilateral founders" as cells that would (i) have a bilateral counterpart (in position), (ii) produce bilaterally symmetrical clonal progeny with similar lineage tree topology, and (iii) appear at roughly the same developmental time point. Following this definition, we identified not only few, but a whole array of 11 pairs of bilateral founders situated on the right and left sides of the Platynereis episphere (Fig. 5A). These appear in succession, starting as early as $6 \mathrm{hpf}$ and continuing to arise until $18 \mathrm{hpf}$ (Additional file 14: Figure S4). These bilateral founders produce clonal progeny that covers large part of the episphere at 32 hpf (Fig. 5A, A' and Additional files 4 and 7).

Using our tracked lineage, we then determined how these 11 pairs of bilateral founders relate back to the lineage of the spiral cleavage pattern. Previous reports on Nereis [18] and Platynereis [26, 34] identified the first divisions with bilateral symmetry starting from $7 \mathrm{hpf}$, yet could not track the progeny of these cells at subsequent stages. Using our tracked lineage, we identified the first "bilateral" divisions (i.e., divisions with a bilaterally rather than rotationally symmetrical orientation of spindle poles) and determined their clonal progeny. Succeeding the fourth spiral cleavage, the $1 \mathrm{~m}-112$ cells are the first to divide bilaterally around $6 \mathrm{hpf}$, producing two bilaterally positioned daughter cells $(1 \mathrm{~m}-1121$ and $1 \mathrm{~m}-1122)$ (Fig. 5B). Of these, the more peripherally located cells $1 \mathrm{~m}-1122$ (blue in Fig. 5B) represent the first bilateral founder pairs ( 4 and 9). Around $8 \mathrm{hpf}$, the more medial $1 \mathrm{~m}-1121$ cells divide again in a bilaterally symmetrical manner (Fig. 5C; with lineage homologs of $\mathrm{C} / \mathrm{D}$, and $\mathrm{A} /$ $B$ quadrants shown in similar color). This results in 4 

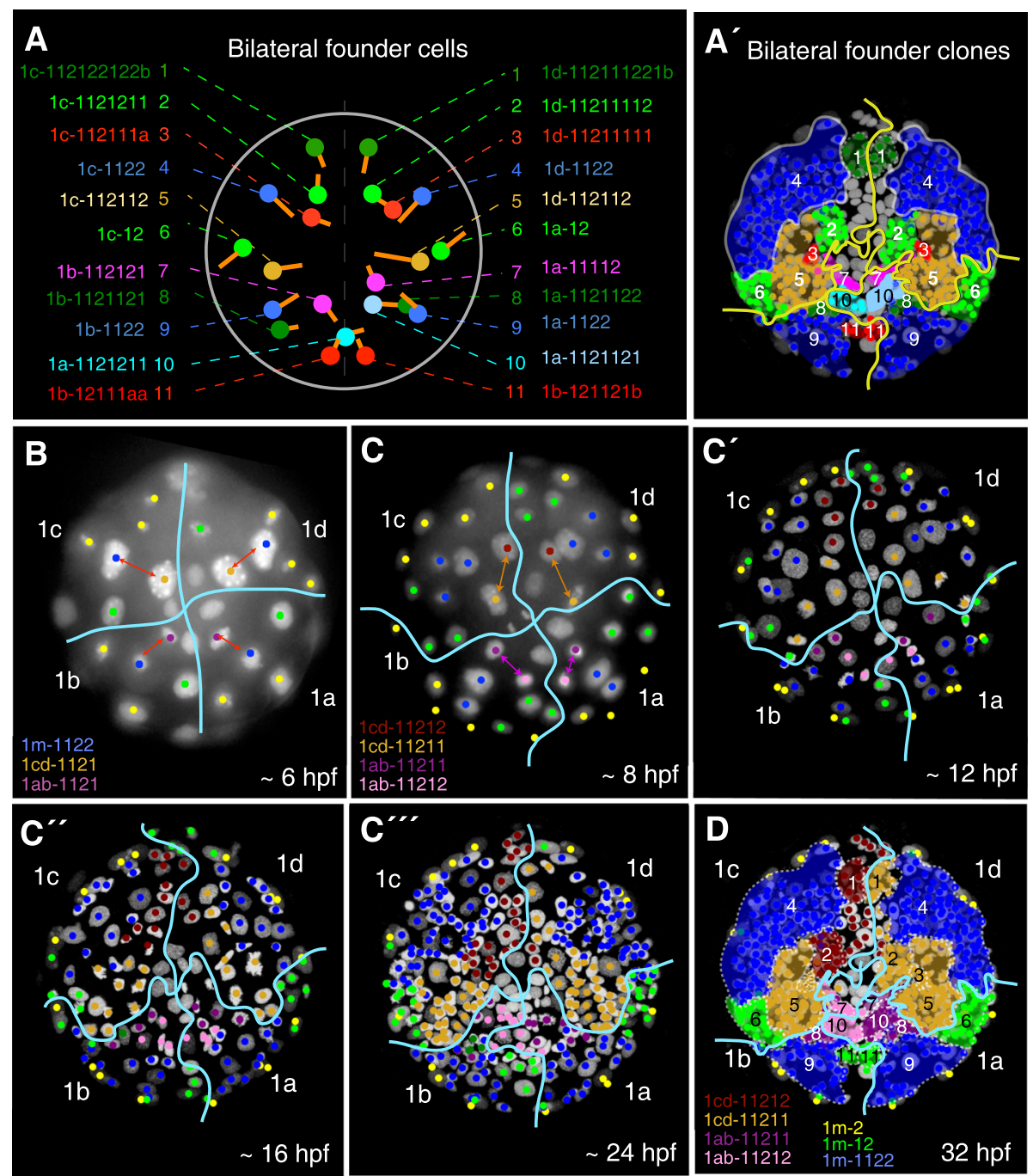

Fig. 5 Bilateral founder cells in the episphere. A The map of bilateral founder cells summarizes the position of all bilateral founders over time. The orange lines represent the division axis between the bilateral founder (colored spot) and its sister cell. The full lineage name is given for each bilateral founder. $\mathbf{A}^{\prime}$ The clonal offspring of the bilateral founders at $32 \mathrm{hpf}$, domains numbered according to panel $\mathbf{A}$. The tracks with the same coloring is available in Additional files 4 and 7. B-E The first bilaterally symmetric divisions do not produce bilaterally symmetric clones. The offspring of the early bilaterally dividing cells at $6 \mathrm{hpf}(\mathbf{B})$ and $8 \mathrm{hpf}(\mathbf{C})$ was highlighted with different colors and their clonal domains were followed until $32 \mathrm{hpf}\left(\mathbf{C}^{\prime}-\mathbf{C}^{\prime \prime \prime}, \mathbf{D}\right)$. Note the asymmetrical domains produced by the medial quadrant homologues $1 \mathrm{~m}-11212$ and $1 \mathrm{~m}-11211$ contrasting with the bilateral domains produced by the lateral quadrant homologues $1 \mathrm{~m}-1122$, and the medial region completely devoid of symmetrical clones. See Additional file 14: Figure S4 for more details

pairs of bilaterally arranged micromeres (1cd-11211; 1cd11212; 1ab-11211; 1ab-11212). Of these, the two dorsal pairs (1cd-11211; 1cd-11212) give rise to the bilateral founder pairs 1, 2, 3, and 5 (Fig. 5A), whereas the two ventral pairs (1ab-11211; 1ab-11212) give rise to bilateral founder pairs 7, 8, and 10 (Fig. 5D, with quadrant homologs shown in similar color). Unexpectedly, however, this occurs in a highly asymmetric fashion: Both the dorsal and the ventral pairs proliferate differentially and expand into different episphere territories (Fig. $5 \mathrm{C}-\mathrm{C}$ '”), so that bilateral founders $1,2,3,7,8$, and 10 arise from noncorresponding lineages (compare to Fig. 5A).
Our analysis thus revealed that the transition from rotational to bilateral symmetry involved very different strategies for different bilateral founder clones: The bilateral founders located more laterally (blue domains 4 and 9 in Fig. 5A') show an equivalent lineage history between right and left quadrants, whereas the bilateral founders located more medially (domains $1,2,3,7,8$, 10, and 11 in Fig. 5A') arise from non-equivalent lineages (Fig. 5A', D and Additional file 14: Figure S4).

Finally, we noted a peculiar difference in how the four initial quadrants $1 \mathrm{a}, 1 \mathrm{~b}, 1 \mathrm{c}$, and $1 \mathrm{~d}$ contributed to the multiple pairs of bilateral founders. Overall, the cell 
clones originating within the 1c quadrant are bilaterally symmetrical to the clones of the $1 \mathrm{~d}$ quadrant, and the clones originating in the $1 \mathrm{~b}$ quadrant are symmetrical to the clones of the 1a quadrant. In a few rare cases, however, pairs of bilateral founders came from the 1a versus 1c quadrants (lateral light green clone no. 6 in Fig. 5A' and $\mathrm{D}$ ), or originated from a single quadrant (light and dark blue clones in Additional file 14: Figure S4C and dark green clones in Additional file 14: Figure S4D). These results demonstrate that the overall bilaterally symmetric Platynereis episphere at $32 \mathrm{hpf}$ originates as a patchwork of different clonal domains showing spiral, bilateral, and no symmetry.

Early six3 and otx expression matches spiral lineage quartets A number of recent studies have revealed a conserved role of the homeodomain transcription factors six 3 , otx, and $n k 2.1$ in the specification of the apical region [14, $33,35]$. In general, a ring of six 3 expression occurs most apically, surrounded by another ring of otx expression. $N k 2.1$ is expressed in the ventral apical region, overlapping partially with six 3 and otx. Taking advantage of our cellular atlas, we set out to characterize the developmental lineage of the six3, otx , and $n k 2.1$-expressing cells. At $6 \mathrm{hpf}$, otx is expressed in the $1 \mathrm{~m}-12$ primary trochoblast cells (Additional file 15: Figure S5), which later give rise to the accessory prototroch. At $12 \mathrm{hpf}$, the cells expressing otx match the $1 \mathrm{~m}-1122$ descendants with few exceptions (Fig. 6c, e), thus including the bilateral founders that produce the set of bilateral clones with equivalent lineages (representing quadrant homologs, compare Fig. 5D). This means, the early otx domain develops from specific quartets of micromeres, which is in line with a possible specification by maternal determinants.

In contrast, at $12 \mathrm{hpf} \operatorname{six} 3$ expression matches the $1 \mathrm{~m}$ 1121 quartet (Figs. 6a and 5B), which produces bilateral founders with non-equivalent lineages (compare Fig. 5D). Just like the early otx domain, this would allow the early
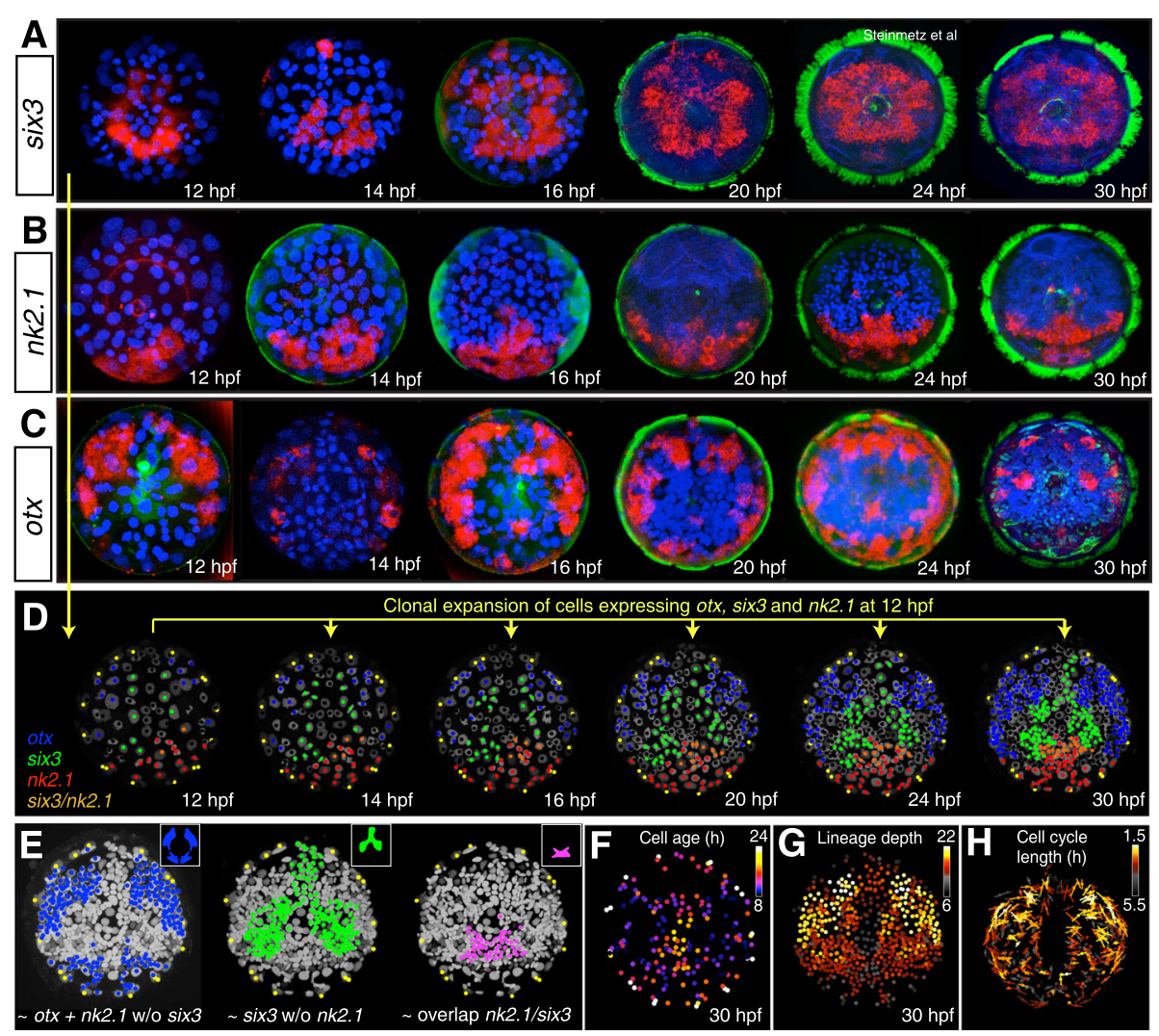

Fig. 6 Developmental expression patterns of ancestral early patterning genes. a-c Representative developmental expression of six3 (a), nk2.1 (b), and otx (c) between 12 and 30 hpf. $\mathbf{d}$ The expression of the three genes otx (blue), six3 (green), and nk2.1 (red) mapped on the lineage movie at $12 \mathrm{hpf}$ and the clonal offspring of these cells visualized at later stages. Cells expressing both six 3 and $n k 2.1$ are labeled in orange. e Whereas the otx and $n k 2.1$ clonal domain reflects the lateral regions adopting bilateral symmetry very early (compare to Figs. 5A' and 7D), the six3 domain encompasses the medial region with later and lineage-unrelated origin of bilateral symmetry (compare to Fig. 7C and D). $\mathbf{f}$ Visualization of cell age (time from the last division) at $30 \mathrm{hpf}$ reveals the prototroch and the apical organ as the earliest differentiating regions of the episphere (compare to expression of the neural markers in Additional file 12: Figure S3). $\mathbf{g}$ Analysis of the lineage depth (the number of preceding cell divisions of a given cell, starting from the zygote until the given time point) identifies the lateral regions as the most proliferative in accordance to the shortest cell cycle length $(\mathbf{h})$ 
six3 domain to be set up by maternal determinants inherited by the respective quartet. However, in contrast to the otx + domain, the bilateral founders emanating from six $3+$ domain do not represent quadrant homologs and are thus unlikely to be specified maternally.

The $12 \mathrm{hpf} n k 2.1+$ clones are partially co-expressing otx and six3. The $n k 2.1+$ clones represent the region with the highest disorder with regard to bilateral founder cells. Notably, the ancestral patterning genes six3, otx, and $n k 2.1$ are absent from the early differentiating apical organ cells that stem from the $1 \mathrm{~m}-111$ lineages.

\section{Larval six 3 and otx expression matches bilateral clones}

We next analyzed and compared the expression domains of $s i x 3$, otx , and $n k 2.1$ at later developmental time points up to $30 \mathrm{hpf}$ (Fig. 6a-d). At these larval stages, the six 3 and otx expression domains largely remain mutually exclusive, except for a paired domain of overlap left and right of the apical organ (stars in Fig. 6a and c). However, comparing the later expression domains to the clonal progeny of the early six $3+$, ot $x+$, and $n k 2.1+$ cells, we noted that the later six3 expression spreads into the otx clonal descendants (compare Fig. 6a and d at 24 hpf), while otx expression is largely turned off in these cells from $20 \mathrm{hpf}$ onwards. Nk2.1 expression is less dynamic and largely remains expressed in the clonal descendants of its earlier expression (compare Fig. 6b, d). Therefore, while the complementary nature of the ringshaped six 3 and otx domains persists, they appear to shift across the episphere so that they no longer match quartet descendants.

We noted that at larval stages, the six 3 and otx domains more closely matched the outlines of bilateral clones and subclones. For example, at $30 \mathrm{hpf}$, the ventral stripe of six 3 expression largely covered the bilateral founder clones 5, 8, and 10 (compare Figs. 5F and 6a). In addition, the dorsal patches of six 3 expression appeared to match large lineage subclones of the bilateral founder clones 4 (compare Figs. 5F and 6a; green and bright blue subclones in Additional file 14: Figure S4A). The paired patches of six 3 and otx co-expression similarly matched a subclone of the bilateral founder clone 5 (compare Figs. 5F and 6c; light brown subclone in Additional file 14: Figure S4B).

Characterizing the six 3 , otx, and $n k 2.1$ domains further, we noted that the six 3 cells generate several differentiated cells at $22 \mathrm{hpf}$, including the crescent cell (no. 40 in Table 1 and Fig. 2f), six 3 ventral ChAT + cells (no. 47, 48, 49, 50, 51, 52 in Table 1) (partially co-expressing $n k 2.1$ ), and one serotonergic cell (no. 53 in Table 1). In line with early differentiation, the six 3 cells divide less on average (compare Fig. 6e, g). In contrast, the dorsal otx domain is the most proliferative among episphere cells in that it shows the highest lineage depth and the shortest cell cycle length (Fig. 6g, h). Except for the prototroch and accessory prototroch cells, it produces no differentiated cells until $22 \mathrm{hpf}$ (whereas the ventral cells 1ab-1122 give rise to the gland cells, Table 1). Cells in this territory differentiate much later, such as the adult eyes [36].

\section{Discussion}

We have tracked the full cell lineage of the larval episphere in the marine annelid Platynereis dumerilii, from spiral cleavage to fully bilateral larval stages, including individual lineages for 62 differentiated cells. Overall, our data confirm earlier observations that the development of spirally cleaving embryos is highly stereotypic at early stages (up to $6 \mathrm{hpf}$ ), and extend the notion of stereotypicality to larval stages. Consistent with this, we find that the cell lineage of early differentiating cells is highly invariant.

To relate the Platynereis lineage to gene expression and cell identities, we built a gene expression atlas for embryonic and early larval stages, for 23 genes with known roles in developmental specification and cellular differentiation. This is part of ongoing efforts [25, 32, 37, 38] to resolve and understand Platynereis development at single cell level. The comparison of our new resources to similar pioneering efforts in other developmental models (e.g., [39-43]) will be especially rewarding for our understanding of conservation and divergence in gene expression profiles and cell types among spiralians.

\section{Rotational symmetry of early differentiating larval cells}

Our lineage analysis corroborates earlier findings that the early differentiating prototroch cells have a strictly spiral origin, and we further show how the diverse, early-appearing cells of the apical organ each emerge from most apical micromeres, via dissimilar lineages. Earlier work in Platynereis [44] and early cell dissociation experiments in Nereis [45] pointed to a high degree of cell autonomous differentiation for these cells via the inheritance of maternal determinants, and in line with this, several studies in mollusks [46-48] and in Platynereis [49] demonstrated that mRNA segregation into specific blastomeres during the cleavage plays a crucial role in cell autonomous specification.

We further show that the spiral and bilateral division patterns co-exist for a certain period, with the first bilateral divisions beginning at $\sim 6 \mathrm{hpf}$ while the last spiral divisions of accessory prototroch cells take place at $\sim 8 \mathrm{hpf}$. In line with the notion that the zygotic expression is necessary for the first bilaterally symmetric division in the leech Helobdella [50], we did not observe any bilateral behavior before the onset of zygotic transcription [51]. 


\section{Highly complex transition from rotational to bilateral symmetry}

Our full lineage analysis until $32 \mathrm{hpf}$ has allowed the first in-depth investigation of the transition from the embryonic spiral cleavage pattern with rotational symmetry to the bilateral symmetry of the early juvenile. As anticipated by Wilson [18], we find that the bilaterally symmetrical parts of the larval body emerge from socalled bilateral founders. However, the generation of these bilateral founders from the four rotational quadrants is surprisingly complicated (Fig. $7 \mathrm{a}-\mathrm{c}$ ). First, the more lateral bilateral founders emerge from equivalent lineages in different quadrants, located on the future left and right body sides. Most of these are located in quadrants $\mathrm{A}$ and $\mathrm{B}$ (A|B symmetry), or in $\mathrm{C}$ and $\mathrm{D}$ (C|D symmetry, red regions in Fig. 7c), whereas one bilateral founder pair is shared between A and $\mathrm{C}(\mathrm{A} \mid \mathrm{C}$ symmetry, blue regions in Fig. 7c). Remarkably, while the $\mathrm{A} \mid \mathrm{C}$ bilateral symmetry is less frequent in Platynereis and in other annelids such as Capitella [24], it has shown to be predominant in the mollusks Ilyanassa and Crepidula $[15,52]$. Second, sets of bilateral founders can emerge from two cells of dissimilar (non-corresponding) lineage in left-right opposing quadrants (green regions in Fig. 7c), involving non-bilateral cell divisions at non-related positions within the lineage tree topology (Additional file 14: Figure S4). Third, and even more intriguing, we also observed "single quadrant bilateral symmetry," where two symmetric clones originate from the same quadrant (brown regions in Fig. 7c). These findings contradict the initial assumptions [18] that simple bilaterally symmetric divisions should establish the bilaterally symmetric portions of the larval body, as observed for the $2 \mathrm{~d}-112$ and $4 \mathrm{~d}$ somatic descendants in the larval hyposphere/trunk.

The disconnection between quadrant lineage and bilateral founders in medial regions suggests that the specification of these founders could be regulative (rather than mosaic) - triggered for example by a signaling source positioned in the plane of the bilateral symmetry. An obvious candidate for the signaling center is the $2 \mathrm{~d}$ cell and its descendants, positioned in the anterior part of the dorsal hyposphere on the axis of the bilateral symmetry. These cells are well known for their organizing potential of Platynereis trunk [49], and significantly, the deletion of the $2 \mathrm{~d}$ cell in Capitella leads to loss of bilateral symmetry in the head [53]. Interestingly, the regulative potential of the $\mathrm{D}$ quadrant does not seem to be limited to the $\mathrm{C}|\mathrm{D}-\mathrm{A}| \mathrm{B}$ bilateral symmetry, but might also contribute to establishing the $\mathrm{A} \mid \mathrm{C}$ bilateral symmetry, as demonstrated by its involvement in specification of the $\mathrm{A}$ and C quadrant-derived eyes in Ilyanassa [54].

\section{Conserved six $3+$, otx + , and $n k 2.1+$ head regions show distinct lineage behavior}

Across Bilateria, the homeobox gene six3 plays an evolutionary conserved role in the specification of the most apical body region, peripherally abutting the ot $x+$ expression territory. The expression of $n k 2.1$ overlaps six 3
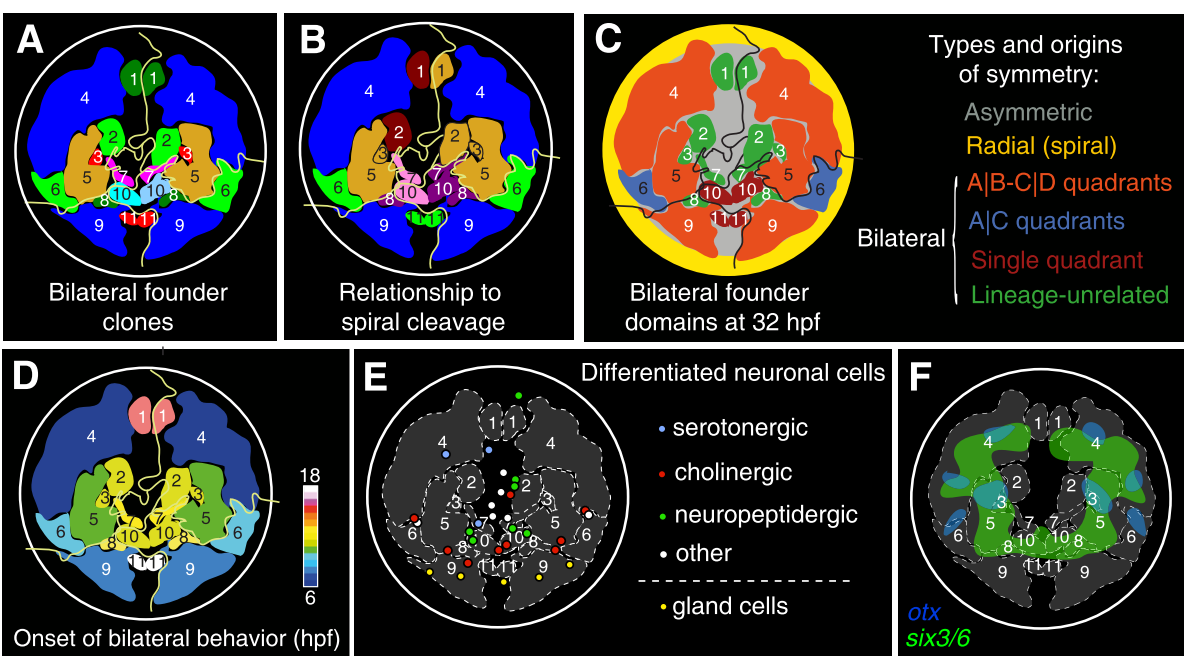

Fig. 7 Relationship between bilateral founder domains, cell differentiation, and otx-six3/6 expression. a Schematic representation of the bilateral founder domains at $32 \mathrm{hpf}$ with a color code reflecting bilateral symmetry (compare to Fig. 5A'). b Schematic representation of the bilateral founder domains color-coded by quadrant homology (compare to Fig. 5D). c A summary diagram of the types of symmetry in the episphere. The bilateral founder pairs are color-coded by the type of symmetry behavior (left panel) and their clonal domains at 32 hpf. $\mathbf{d}$ Bilateral founder cells originate at different time points during development, highlighted by the temporal color-coding of their clonal domains. Note that the peripheral areas (dark and light blue) are the first to adopt the bilateral behavior. The areas along the dorso-ventral axis (yellow, red, and white) are the last ones to adopt bilateral behavior. e The position of differentiated cell types (compare to Fig. 3F) within the bilateral founder domains. $\mathbf{f}$ The overlay of the otx and six3/6 expression and the bilateral founder domains at $32 \mathrm{hpf}$ 
and otx expression on the ventral body side [14, 35, 55]. Mapping the expression of these genes on the tracked lineages, we observe an almost perfect match between expression regions and groups of cells with distinct (but internally consistent) lineage behavior. In particular, we notice that the combined expression of six 3 , otx, and $n k 2.1$ encompasses all bilateral founders that arise from the $1 \mathrm{~m}-1121$ and $1 \mathrm{~m}-1122$ micromeres and thus all lineages of subsequently differentiating cells with bilateral symmetry-at least transitorily. Among these, six3 expression labels the more medially located $1 \mathrm{~m}-1121$ founders that are of different lineage in opposing quadrant, whereas otx labels the more lateral bilateral founders that stem from $1 \mathrm{~m}-1122$ micromeres, with similar lineages between quadrants. This observation opens up the possibility that six 3 and otx play an early role in determining the divergent lineage behavior of medial versus lateral bilateral founder cells during the spiral-tobilateral transition. In line with this assumption, the medial micromeres that do not transition to bilateral symmetry are devoid of six3, otx, and $n k 2.1$ expression.

\section{The conserved six $3+$ and otx+ domains give rise to cholinergic brain neurons and head sensory organs}

At later larval stages, six3 and otx retain their antagonistic expression, yet transition clonal boundaries, so that the ring of six 3 expression expands to cover large part of the differentiating brain, whereas otx expression becomes restricted to few patches of cell in the periphery. Six3 expression thus labels the bilateral sets of differentiating cholinergic neurons involved in the control of larval ciliary beating [12]. Interestingly, six 3 is expressed in cholinergic forebrain neurons in vertebrates [56] and in the central complex in the insect brain [57], which also contains cholinergic neurons [58]. A possible conservation of these cholinergic neuron types and their possible ancestral function can be tested by a broader comparative analysis of these neurons in other animals.

Mapping the gene expression atlas onto the larval Platynereis lineage yields another important insight. At 12 hpf, a small population of $p h c 2+$ neuropeptidergic cells is found near the plane of bilateral symmetry in the dorsal embryo. Our atlas reveals that these cells are early representatives of a larger $p h c 2+$ population that is constantly present around the apical organ at 34 hpf (Additional file 12: Figure S3). This population in turn expands to the population of $p h c 2+$ cells present in the 48 hpf brain (termed "apical nervous system"; $[32,55]$ ). Our integrated analysis reveals that, while some of these cells initially express six 3 , the gene is later turned off in these cells, so that the $p h c 2$ expression domain largely matches the medial "hole" free of six 3 expression in the middle of the episphere [14], with the exception of few marginal cells co-expressing phc2 and six3 [32]. We and others have compared the phc2-expressing cells in the medial forebrain of invertebrates to the hypothalamus in vertebrates-which is likewise surrounded by the six3expressing cholinergic forebrain [12].

In contrast to the six $3+$ bilateral founders, the otx + bilateral founders proliferate heavily during later stages and differentiate much later, into adult eyes and optic lobes [36], indicating that the $o t x+$ cells contribute to head sensory organs rather than cerebral ganglia. Together, these findings indicate that the ring of six 3 expression in the larval episphere gives rise to large part of the cerebral ganglia, whereas sensory organs and associated brain centers emerge from more lateral $o t x+$ territory and medial neurosecretory centers from the most apical region devoid of $\operatorname{six} 3$ expression.

\section{Lineage comparison to other spiralians}

Finally, our data allows comparing the lineage of similar cells with particular identities between Platynereis and other spiralian species. For example, the lineage of the accessory trochoblasts is traditionally reported as $1 \mathrm{~m}-12$ [23, 26]. The descendants of $1 \mathrm{~m}-12$ form differentiated accessory prototroch cells (1m-122 and $1 \mathrm{~m}-1212)$, characterized by a tight association with primary prototroch cells. Interestingly, their cell lineage in Platynereis is different from accessory trochoblasts in the polychaetes Amphitrite and Podarke (1a-2222, 1c-1222) but partially similar to the mollusk Dentalium [10]. In Platynereis, the progeny of $1 \mathrm{~d}-12$ does not only give rise to one accessory prototroch cell, but some migrate posteriorly to contribute to the antero-median part of the dorsal hyposphere, as reported for other polychaetes [10] and references therein. The Platynereis cell lineage $(1 \mathrm{c} / \mathrm{d}-$ 11221) migrating laterally and forming the "head kidneys" posteriorly to the prototroch agrees with previous reports for Nereis [18].

The spiralian apical organ is assumed to generally derive from the apical rosette cells, although actual cell lineage studies are mostly lacking [59]. The cells forming the apical tuft in Platynereis are 1c-1111/1c-1112 (the ampullary cells) and 1d-1111/1d-1112 (the large apical dorsal cell and first apical axon-projecting cell), and thus indeed derived from apical rosette. Similarly, in the mollusk Dentalium, the $1 \mathrm{a}^{111}-1 \mathrm{~d}^{111}$ and $1 \mathrm{a}^{1121}-1 \mathrm{~b}^{1121}$ contribute to the apical organ, with the apical tuft developing from $1 \mathrm{c}^{1111}$ and $1 \mathrm{~d}^{1111}[10]$.

\section{Outlook}

Our data yields first insight into the interplay between cellular lineage and gene regulatory networks in spiralian development, spanning the transition from embryonic and larval rotational symmetry to the bilateral symmetry of the juvenile. Future lineage data extending beyond 32 hpf will be integrated with refined expression atlases 
generated through Profiling by Signal Probability Mapping (ProSPr [25];), and with single-cell expression data mapped onto the expression atlases for reference embryonic and larval stages [32]. This will allow the identification of candidate signals and receptors, as well as the gene regulatory networks establishing bilateral symmetrical behavior and cell fates in spiralian development.

\section{Materials and methods}

\section{Animals}

The larvae of Platynereis dumerilii were obtained from the breeding culture at EMBL Heidelberg.

\section{Injections and time-lapse imaging}

The injections of mRNAs encoding for H2A-RFP (courtesy of the Gilmour lab, EMBL Heidelberg) and LynEGFP proteins [27] were performed as described previously [60]. For tracking axonal projections, lifeact-egfp mRNA [61] was injected at concentration $200 \mathrm{ng} / \mu \mathrm{l}$ into a given blastomere of embryos injected previously at 1cell stage with mRNA encoding H2A-RFP protein.

The injected embryos were kept in filtered seawater at $18^{\circ} \mathrm{C}$ until the desired developmental stage was reached. Selected embryos were then transferred in $\sim 2 \mu \mathrm{l}$ of sea water into $40{ }^{\circ} \mathrm{C} \quad 0.8 \%$ low-melting agarose (A9414, Sigma-Aldrich), briefly mixed by pipetting up and down and quickly transferred in $\sim 20 \mu \mathrm{l}$ agarose to the microscopy slide with $150 \mu \mathrm{m}$ spacer on each side (3 layers of adhesive tape Magic ${ }^{\mathrm{Tm}}$ Tape, Scotch $\left.{ }^{\circ}\right)$. Before the agarose fully solidified (within $\sim 15 \mathrm{~s}$ ), the embryos were covered by a coverslip and oriented to the apical position for imaging. Seawater was added from the side of the slide to entirely fill the slide chamber. To avoid drying out, the coverslip was sealed using mineral oil. Embryo 1 and embryo 2 were imaged using a Zeiss Axio Imager, $\times 40$ oil immersion objective, with $0.48-\mu \mathrm{m} X Y$ resolution and $1-\mu \mathrm{m} z$ resolution. Other embryos were imaged with a M1 fluorescent microscope or Leica TCS SPE confocal microscope with $\times 40$ oil immersion objective. The imaging on the confocal microscope was performed with $1.5-\mu \mathrm{m} \mathrm{z}$ resolution for all embryos, and 0.414- $\mu \mathrm{m} x y$ resolution (embryo 3), $0.384-\mu \mathrm{m}$ xy resolution (embryo 10 ), and $0.387 \mu \mathrm{m}$ (embryo 11). The formal time resolution of the recordings is as follows: $6 \mathrm{~min}$ (embryo 1), 12 min (embryo 2), 12 min (embryo 3), 9 min (embryo 10 ), and $8 \mathrm{~min}$ (embryo 11). However, due to the heat produced by the imaging and instability of the temperature in the microscopy room, the imaging time does not directly relate to the developmental time. To compensate for this, the live-imaging movies were calibrated using the episphere nuclei counts from embryos freely developing in $18{ }^{\circ} \mathrm{C}$ sea water and fixed at given developmental time $(5,10,12,14,16,20,24$, and 30 hpf), stained with DAPI and imaged using confocal microscopy. The calibrated developmental time is timestamped on the reference lineage movies 1 and 2 (Additional files 3 and 6, as well as the Z-projections of 4D recording of each embryo, available in the online data repository [28]). After imaging, the embryos were quickly assessed for viability (coordinated ciliary beating, spiral swimming, gross morphology) using wide-field microscopy and immediately fixed. Misdeveloping embryos were excluded from subsequent analyses.

\section{Tracking and comparing the cell lineage across multiple embryos}

The live-imaging movies were manually tracked using a custom-made tracking macro in ImageJ/FiJI [29]. We used the nuclei count of the episphere in embryos precisely fixed at several time points to calibrate the developmental time in the movies. Due to a high density of nuclei at later stages, we were able to reliably track until about 32 hpf. At early developmental stages, we use the standard spiralian nomenclature of the cells according to [62]. After $6 \mathrm{hpf}$, even for non-spiral cell divisions, we use the index 1 for the more anterior and index 2 for the more posterior daughter cell until around $10 \mathrm{hpf}$. After 10 hpf, we use indices "a" and "b" instead of " 1 " and "2," to emphasize that the cells do not divide in the spiralian cleavage pattern any more. Within the spiral cleavage phase, we use the abbreviated form $1 \mathrm{~m}$-xyz to collectively refer to all four quadrant homologs (i.e., cells 1a-xyz, 1b-xyz, 1c-xyz, and 1d-xyz).

\section{Comparing the lineage of multiple embryos}

To compare the cell lineage across different embryos, a simple algorithm automatically identifying corresponding cells in each tracking dataset and highlighting the differences was used (Additional file 9: Figure S1F): First, the corresponding cells were manually assigned in the first frames of the 4D recordings, representing the roots of the lineage trees. Subsequently, at the earliest following cell division, several "features" (relative spatial position of the daughter cells, subsequent cell cycle length, and number of descendants of each of the two daughter cells) were extracted. These features are then used to generate a feature matrix for each pair of daughter cell in various embryos. The feature matrices are then compared among daughter cells from different embryos using weighting coefficients (determined arbitrarily) that results in a similarity score (Additional file 9: Figure S1F). The cells with the highest similarity score are then assigned to be corresponding cells between the two embryos and thus provide the new rooting point for the next repetition of the same procedure. The decision procedure is then performed for the following cell division, identifying the corresponding cells, and proceeds throughout the entire lineage trees until all corresponding cells are identified. 
As the 4D recordings cover the first $\sim 34 \mathrm{hpf}$ of development, there are still many cell divisions to come after the last frame of the recordings. Due to the increasing asynchrony between division timing (Additional file 9: Figure $\mathrm{S} 1 \mathrm{H}$ ), corresponding cell divisions can occur before the end of the $4 \mathrm{D}$ recording in one embryo but after the last frame of the 4D recording in another embryo, leading to a false difference in the comparison (Additional file 9: Figure S1G-G'). To avoid this problem of overestimating the number of differences, the recordings were compared at $30 \mathrm{hpf}$, and the remaining recording frames were used "known divisions to come." We estimated a safe time point to compare the recordings to be $30 \mathrm{hpf}$ ( $\sim 3 \mathrm{~h}$ before the last recorded time frames), since the average of maximum difference in cell division across the three time-lapse recordings increases with developmental time and reaches about $2.5 \mathrm{~h}$ between 30 and 34 hpf (Additional file 9: Figure $\mathrm{S} 1 \mathrm{H}$ ).

\section{Whole-mount mRNA in situ hybridization}

The mRNA in situ hybridization was performed as described in [63] with the following modifications: For developmental stages earlier than $12 \mathrm{hpf}$, the embryos were washed twice $4 \mathrm{~min}$ with calcium/magnesium-free sea water [64] prior to fixation. For developmental stages younger than $24 \mathrm{hpf}$, the embryos were acetylated: After the digestion in proteinase $\mathrm{K}$ and two washes with freshly prepared $2 \mathrm{mg} / \mathrm{ml}$ glycine in PTW $(1 \times$ phospate-buffered saline with $0.1 \%$ Tween-20), the embryos were incubated $5 \mathrm{~min}$ in $1 \%$ triethanolamine in PTW, then $3 \mathrm{~min}$ in $1 \%$ triethanolamine with $0.2 \%$ acetic anhydride followed with $3 \mathrm{~min}$ of $0.4 \%$ acetic anhydride in 1\% triethanolamine. The prehybridization, hybridization, and SSC washes were performed at $63^{\circ} \mathrm{C}$. The hybridization mixture: 50\% Formamide (Sigma-Aldrich, F9037), 5× SSC $\mathrm{pH} 4.5,50 \mu \mathrm{g} / \mathrm{ml}$ Heparin (Sigma-Aldrich, H3149), 0.025\% Tween-20 (Sigma-Aldrich, P9416), $50 \mu \mathrm{g} / \mathrm{ml}$ Salmon Sperm DNA (Sigma-Aldrich, D9156), 1\% SDS. The antisense mRNA probes for chat and elav [65]; syt, tph, phc2, and $n k 2.1$ [33]; vacht [13]; otx [66]; six3/6 [35]; and vglut [37] were DIG-labeled using DIG RNA Labeling Mix (Roche, 11277073 910). Typically, 10-20 embryos were processed per developmental stage and gene, and 23 embryos imaged using confocal microscopy. For mapping gene expression onto the reference movies, 2-3 embryos were imaged after WMISH using the reflection of NBT/BCIP precipitate [67] and counterstained with DAPI to reveal nuclei and acetylated tubulin to facilitate orientation based on the ciliary band. The mouse anti-acetylated Tubulin antibody (Sigma, T6793) was used at 1:500 dilution and detected by secondary Alexa488-conjugated antimouse antibody (Jackson ImmunoResearch, 115-546062, 1:500). Then, the DAPI channel was used and carefully compared to the 3D stack of the reference movie at corresponding developmental stage. Corresponding nuclei were identified based on their shape, staining intensity, and relative position.

\section{Supplementary information}

Supplementary information accompanies this paper at https://doi.org/10. 1186/s12915-019-0705-X.

Additional file 1. The ImageJ/FIJl macro package for visualization of the lineages using the tracking data and the lineage movies. The macro package allows visualizing the track on top of the lineage movies, finding a given cell by the lineage name or the reference ID name, changing colors of a given cell, its descendants and/or ancestors. Documentation is provided in Additional file 2.

Additional file 2. The documentation to the Additional file 1: PduLineageMacroPackage.ijm macro package contains instructions how to install the macro package and use it functions.

Additional file 3. The movie is a z-projection of combined live-imaging recordings of Embryo 1, Embryo 2 and Embryo 3) and shows the development of the episphere from $\sim 6$ hpf until $\sim 33$ hpf. Could be opened by the ImageJ/FIJI software [29]. The original 4D recordings of the embryos are available in online data repository [28].

Additional file 4. The track of the Additional file 3:

Reference_Lineage_Movie1.tif contains the xyzt coordinates of the cells, their lineage names and reference ID names. The coloring scheme of the track corresponds to the coloring of bilateral founders in Fig. 5A-A'. The track can be visualized on top of the movie using the Additional file 2 .

Additional file 5. This file is a $7 z$ archive of the lineage trees of the Reference_Lineage_Movie1. The particular tree files are in scalable vector graphics format (.svg). The coloring scheme of the track corresponds to the coloring of bilateral founders in Fig. 5A-A'.

Additional file 6 . The movie is a z-projection of combined live-imaging recordings of Embryo 1 and Embryo 10) and shows the development of the episphere from $\sim 6$ hpf until $\sim 33$ hpf. Could be opened by the ImageJ/FIJI software [29]. The original 4D recordings of the embryos are available in online data repository [28].

Additional file 7. The track of the Additional file 6 :

Reference_Lineage_Movie2.tif contains the xyzt coordinates of the cells, their lineage names and reference ID names. The coloring scheme of the track corresponds to the coloring of bilateral founders in Fig. 5A-A'. The track can be visualized on top of the movie using the Additional file 2 .

Additional file $\mathbf{8}$. This file is a $.7 z$ archive of the lineage trees of the Reference_Lineage_Movie1. The particular tree files are in scalable vector graphics format (.svg). The coloring scheme of the track corresponds to the coloring of bilateral founders in Fig. 5A-A'.

Additional file 9: Figure S1. Comparing the cell lineage among multiple embryos. This supplementary figure provides details about the comparison of the cell lineage among multiple embryos and identifying corresponding cells. (AD) The comparison between the clonal domains revealed by injections of $h 2 a-$ Ifp mRNA into a single blastomere and the clonal domain of the corresponding blastomere highlighted in red using the reference lineage movie at $32 \mathrm{hpf}$. (E) Comparison of the clonal domains originating from the cells present at $13 \mathrm{hpf}$ in three different embryos. (F) Identification of corresponding cells between embryos: Multiple features (number of descendants, time till next cell division, relative cell position of each daughter cell) are extracted from the tracking information at each cell division. The feature arrays are compared between embryos to score the similarity and identify corresponding cells. For more details, see Materials and methods. (G-G) The problem of assessing the differences between incomplete lineage trees: Due to the asynchrony in cell division timing, some of the corresponding divisions can happen after the last frame of a given movie (dashed line) - e.g. the magenta lineage within the blue domain in Lineage 1 divides later and therefore does not represent a real difference in cell 
division pattern. In contrast, the red cells within the green sublineage do not divide in Lineage 2 and therefore represent a real difference. $(H)$ The average maximal difference in timing of corresponding cell divisions across three embryos increases with time, reaching around $2.5 \mathrm{~h}$ at $30 \mathrm{hpf}$. The maximal difference in timing was calculated as the difference between the time point at which the corresponding division occurred earliest among the three embryos, and the latest among the three embryos. The average difference was calculated from all corresponding cell divisions happening within the given hour post fertilization.

Additional file 10: Figure S2. The consensus lineage tree of the episphere development from fertilization until $30 \mathrm{hpf}$. The previously described early cell lineage is highlighted in blue [26]. The black branches represent a consensus of three embryos. If one embryo differs from the remaining two, the tree topology based of the two embryos is shown in gray. The horizontal error bars at cell division time points represent the minimal and maximal time point observed for that cell division. The numbers rNNN (eg. 1214) above the branch represent the unique cell ID that can be used to find/label the cell within the ImageJ/FIJ macro (Additional file 1: PduLineageMacroPackage.ijm). The annotations of the known differentiated cell types from Table 1 are shown at the end points of the branches. See Fig. $2 d$ for more details.

Additional file 11: Table S1. The table contains the list of all cells in the consensus lineage tree (Additional file 10), including the lineage name and the reference ID.

Additional file 12: Figure S3. A gene expression atlas of the episphere between 12 and $34 \mathrm{hpf}$. Contains whole-mount RNA in situ hybridization expression pattern for 23 genes at 7 stages $(12,14,16,20,24,30$ and 34 hpf). (A) The expression of bHLH transcription factors. (B) The expression of $k l f$ and prox transcription factors. (C) The expression of neuronal differentiation markers. All panels are apical views with dorsal side on the top of the panel. Embryos were counterstained with DAPI to reveal the nuclei, axonal projections and ciliary band (green) were visualized using anti-acetylated-tubulin antibody staining.

Additional file 13: Table S2. The list of genes in the WMISH atlas between 12 and $34 \mathrm{hpf}$ (Additional file 12).

Additional file 14: Figure S4. Establishment of bilateral clonal domains. This figure contains the details of the cell divisions and lineage of the bilateral founder cells. (A) The bilateral founders, descending from the $1 \mathrm{~m}-1122$ cells, located more laterally, are generated in a perfect bilateral symmetry, reflected by a bilaterally symmetrical arrangement of the resulting lateral clones. All descendent lineages show full bilateral symmetry, as is apparent from the equivalent lineage history of right and left counterpart clones (bottom panel). (BC) For the bilateral founders in the dorso-medial (B) and ventro-medial (C) regions descending from $1 \mathrm{~m}-1121$ sublineages, the lineage history of the left and right founder is very different. These founders originate at different branches of the quadrant homologue lineage tree and in some cases even differ in the lineage depth (light green, red, and dark green clones in panel B; light green clones in panel C). Two bilateral founder pairs - 1a-1121211 and 1a-1121121 (light and dark blue clone in panel C) and 1b-12111aa and 1b-121121b (dark green in D) originate from single quadrants. Note, that the cell divisions occurring at the lateral-most edge of this largely asymmetrical medial domain produce again symmetrical clones (sand and light brown clones in panel B). (D) The origin of A|C symmetry: The cells $1 \mathrm{~m}-12$ divide spirally to produce accessory prototroch cells $1 \mathrm{~m}-122$ and $1 \mathrm{~m}-1212$. Subsequent cell divisions within 1c-12 and 1a-12 clone occur in a bilateral mode resulting in fully bilateral domains stemming from the $A$ and $C$ quadrant.

Additional file 15: Figure S5. The dynamics of early otx expression. This figure shows the developmental expression of otx between 6 and $12 \mathrm{hpf}$ mapped onto the cell lineage and reveals the dynamic switching of otx during episphere development. Otx expression visualized by WMISH (column next to the lineage trees) was mapped on lineage movie and lineage tree at indicated stages. Corresponding nuclei between the stained embryos and the movie frame (horizontal arrows) were identified manually at these stages. The vertical arrows indicate the theoretical clonal expansion of otx-positive cells at later stages. The comparison of such theoretical clonal expansion of otx-expressing cells at different stages to real expression pattern at a given stage (WMISH panel next to the lineage trees) shows that otx expression is not clonal and that the gene is dynamically switched on/ off between cell cycles. The dynamic on/off switching of early otx expression is apparent in the lineage trees on the right-hand side, where the otx-expressing cells (in red) do not form a continuous lineage.

\section{Acknowledgements}

We thank the members of the Arendt lab and the EMBL Developmental Biology unit for valuable discussions and the members of the EMBL Advanced Light Microscopy Facility for the help and expertise in live imaging and microscopy infrastructure.

\section{Authors' contributions}

PV and DA conceived the study. MHT and MAT established the injection protocol for mRNA injection and live imaging. PV and MAT recorded the embryos. PV developed the scripts for tracking and visualizing the tracking data and lineage trees. PV, KA, and MAT manually tracked the lineage. PV performed the analysis of the lineage and generated the lineage trees and the WMISH dataset. PV and DA wrote the manuscript. All authors read and approved the final manuscript.

\section{Funding}

DA, PV, MAT and KA were funded by the ERC Grant BRAINEVODEVO no. 294810 to Prof. Detlev Arendt, and MHT by the European Molecular Biology Laboratory and the Ministerio de Ciencia e Innovación (ES-2008-236).

\section{Availability of data and materials}

All data presented in this study are included in the published article and the additional files and public data repository: https://doi.org/10.6084/m9. figshare.c.4659302 [28].

\section{Ethics approval and consent to participate}

Not applicable.

\section{Consent for publication}

Not applicable.

\section{Competing interests}

The authors declare that they have no competing interests.

\section{Author details}

${ }^{1}$ Developmental Biology Unit, European Molecular Biology Laboratory, Meyerhofstraße 1, 69117 Heidelberg, Germany. ${ }^{2}$ Max Planck Institute of Molecular Cell Biology and Genetics, Pfotenhauerstraße 108, Dresden 01307, Germany.

Received: 22 July 2019 Accepted: 1 October 2019

Published online: 22 October 2019

\section{References}

1. Gilbert SF. Developmental biology -- NCBI bookshelf. Sunderland: Sinauer associates; 2000

2. Henry JQ. Spiralian model systems. Int J Dev Biol. 2014;58(6-8):389-401.

3. Laumer CE, Bekkouche N, Kerbl A, Goetz F, Neves RC, Sorensen MV, Kristensen RM, Hejnol A, Dunn CW, Giribet G, et al. Spiralian phylogeny informs the evolution of microscopic lineages. Curr Biol. 2017;27(24):3906.

4. Sulston JE, Schierenberg E, White JG, Thomson JN. The embryonic cell lineage of the nematode Caenorhabditis elegans. Dev Biol. 1983;100(1):64119.

5. Nishida H. Cell lineage analysis in ascidian embryos by intracellular injection of a tracer enzyme. III. Up to the tissue restricted stage. Dev Biol. 1987; 121(2):526-41

6. Nakamura MJ, Terai J, Okubo R, Hotta K, Oka K. Three-dimensional anatomy of the Ciona intestinalis tailbud embryo at single-cell resolution. Dev Biol. 2012:372(2):274-84.

7. Lawrence PA, Levine M. Mosaic and regulative development: two faces of one coin. Curr Biol. 2006;16(7):R236-9.

8. Lemaire P. Unfolding a chordate developmental program, one cell at a time: invariant cell lineages, short-range inductions and evolutionary plasticity in ascidians. Dev Biol. 2009;332(1):48-60.

9. Dorresteijn AWC, Ogrady B, Fischer A, Porchethennere E, Boillymarer Y. Molecular specification of cell-lines in the embryo of Platynereis (Annelida). Rouxs Arch Dev Biol. 1993;202(5):260-9. 
10. Nielsen C. Trochophora larvae: cell-lineages, ciliary bands, and body regions. 1. Annelida and Mollusca. J Exp Zool B Mol Dev Evol. 2004;302(1):35-68.

11. Nielsen C. Trochophora larvae: cell-lineages, ciliary bands and body regions. 2. Other groups and general discussion. J Exp Zool B Mol Dev Evol. 2005; 304(5):401-47

12. Tosches MA, Bucher D, Vopalensky P, Arendt D. Melatonin signaling controls circadian swimming behavior in marine zooplankton. Cell. 2014;159(1):46-57.

13. Jekely G, Colombelli J, Hausen H, Guy K, Stelzer E, Nedelec F, Arendt D. Mechanism of phototaxis in marine zooplankton. Nature. 2008;456(7220): 395-9.

14. Marlow H, Tosches MA, Tomer R, Steinmetz PR, Lauri A, Larsson T, Arendt D. Larval body patterning and apical organs are conserved in animal evolution. BMC Biol. 2014;12:7.

15. Hejnol $A$, Martindale $M Q$, Henry JQ. High-resolution fate map of the snail Crepidula fornicata: the origins of ciliary bands, nervous system, and muscular elements. Dev Biol. 2007;305(1):63-76.

16. Lyons DC, Perry KJ, Henry JQ. Morphogenesis along the animal-vegetal axis: fates of primary quartet micromere daughters in the gastropod Crepidula fornicata. BMC Evol Biol. 2017;17(1):217.

17. Goulding MQ. Cell lineage of the llyanassa embryo: evolutionary acceleration of regional differentiation during early development. PLoS One. 2009:4(5):e5506

18. Wilson EB. The cell-lineage of Nereis. A contribution to the cytogeny of the annelid body. J Morphol. 1892;6(3):361-481.

19. Fischer AH, Arendt D. Mesoteloblast-like mesodermal stem cells in the polychaete annelid Platynereis dumerilii (Nereididae). J Exp Zool B Mol Dev Evol. 2013;320(2):94-104.

20. Lyons DC, Perry KJ, Lesoway MP, Henry JQ. Cleavage pattern and fate map of the mesentoblast, $4 d$, in the gastropod Crepidula: a hallmark of spiralian development. EvoDevo. 2012:3(1):21.

21. Gline SE, Nakamoto A, Cho SJ, Chi C, Weisblat DA. Lineage analysis of micromere $4 \mathrm{~d}$, a super-phylotypic cell for Lophotrochozoa, in the leech Helobdella and the sludgeworm Tubifex. Dev Biol. 2011;353(1):120-33.

22. Ozpolat BD, Handberg-Thorsager M, Vervoort M, Balavoine G. Cell lineage and cell cycling analyses of the $4 \mathrm{~d}$ micromere using live imaging in the marine annelid Platynereis dumerilii. eLife. 2017;6:e30463. https://doi.org/10. 7554/eLife.30463.

23. Ackermann C, Dorresteijn A, Fischer A. Clonal domains in postlarval Platynereis dumerilii (Annelida: Polychaeta). J Morphol. 2005;266(3):258-80.

24. Meyer NP, Boyle MJ, Martindale MQ, Seaver EC. A comprehensive fate map by intracellular injection of identified blastomeres in the marine polychaete Capitella teleta. EvoDevo. 2010;1(1):8.

25. Vergara HM, Bertucci PY, Hantz P, Tosches MA, Achim K, Vopalensky P, Arendt D. Whole-organism cellular gene-expression atlas reveals conserved cell types in the ventral nerve cord of Platynereis dumerilii. Proc Natl Acad Sci U S A. 2017;114(23):5878-85

26. Dorresteijn AWC. Quantitative-analysis of cellular-differentiation during early embryogenesis of Platynereis-Dumerilii. Rouxs Arch Dev Biol. 1990;199(1):14-30.

27. Haas $P$, Gilmour D. Chemokine signaling mediates self-organizing tissue migration in the zebrafish lateral line. Dev Cell. 2006;10(5):673-80.

28. Vopalensky P, Tosches MA, Achim K, Handberg-Thorsager M, Arendt D: From spiral cleavage to bilateral symmetry: the developmental cell lineage of the annelid brain. Supplementary datasets; figshare 2019: doi: https://doi. org/10.6084/m9.figshare.c.4659302.

29. Schindelin J, Arganda-Carreras I, Frise E, Kaynig V, Longair M, Pietzsch T, Preibisch S, Rueden C, Saalfeld S, Schmid B, et al. Fiji: an open-source platform for biological-image analysis. Nat Methods. 2012;9(7):676-82.

30. Veraszto C, Ueda N, Bezares-Calderon LA, Panzera A, Williams EA, Shahidi R, Jekely G. Ciliomotor circuitry underlying whole-body coordination of ciliary activity in the Platynereis larva eLife. 2017;6:e26000. https://doi.org/10.7554/ eLife. 26000

31. Kratsios P, Stolfi A, Levine M, Hobert O. Coordinated regulation of cholinergic motor neuron traits through a conserved terminal selector gene. Nat Neurosci. 2012;15(2):205-14.

32. Achim K, Eling N, Vergara HM, Bertucci PY, Musser J, Vopalensky P, Brunet T, Collier $\mathrm{P}$, Benes V, Marioni JC, et al. Whole-body single-cell sequencing reveals transcriptional domains in the annelid larval body. Mol Biol Evol. 2018;35(5):1047-62

33. Tessmar-Raible K, Raible F, Christodoulou F, Guy K, Rembold M, Hausen H, Arendt D. Conserved sensory-neurosecretory cell types in annelid and fish forebrain: insights into hypothalamus evolution. Cell. 2007;129(7):1389-400.
34. Pruitt MM, Letcher EJ, Chou HC, Bastin BR, Schneider SQ. Expression of the wnt gene complement in a spiral-cleaving embryo and trochophore larva. Int J Dev Biol. 2014;58(6-8):563-73.

35. Steinmetz PR, Urbach R, Posnien N, Eriksson J, Kostyuchenko RP, Brena C, Guy K, Akam M, Bucher G, Arendt D. Six3 demarcates the anterior-most developing brain region in bilaterian animals. EvoDevo. 2010;1(1):14.

36. Arendt D, Tessmar K, de Campos-Baptista MIM, Dorresteijn A, Wittbrodt J. Development of pigment-cup eyes in the polychaete Platynereis dumerilii and evolutionary conservation of larval eyes in Bilateria. Development. 2002 129(5):1143-54

37. Tomer R, Denes AS, Tessmar-Raible K, Arendt D. Profiling by image registration reveals common origin of annelid mushroom bodies and vertebrate pallium. Cell. 2010;142(5):800-9.

38. Achim K, Pettit JB, Saraiva LR, Gavriouchkina D, Larsson T, Arendt D, Marioni JC. High-throughput spatial mapping of single-cell RNA-seq data to tissue of origin. Nat Biotechnol. 2015;33(5):503-9.

39. Du Z, Santella A, He F, Shah PK, Kamikawa Y, Bao Z. The regulatory landscape of lineage differentiation in a metazoan embryo. Dev Cell. 2015; 34(5):592-607.

40. Santella A, Kovacevic I, Herndon LA, Hall DH, Du Z, Bao Z. Digital development: a database of cell lineage differentiation in C. elegans with lineage phenotypes, cell-specific gene functions and a multiscale model. Nucleic Acids Res. 2016:44(D1):D781-5.

41. Stach T, Anselmi C. High-precision morphology: bifocal 4D-microscopy enables the comparison of detailed cell lineages of two chordate species separated for more than 525 million years. BMC Biol. 2015;13:113.

42. Tassy O, Dauga D, Daian F, Sobral D, Robin F, Khoueiry P, Salgado D, Fox V, Caillol D, Schiappa R, et al. The ANISEED database: digital representation, formalization, and elucidation of a chordate developmental program. Genome Res. 2010;20(10):1459-68.

43. Vellutini BC, Martin-Duran JM, Hejnol A. Cleavage modification did not alter blastomere fates during bryozoan evolution. BMC Biol. 2017;15(1):33.

44. Dorresteijn AWC, Graffy C. Competence of blastomeres for the expression of molecular tissue markers is acquired by diverse mechanisms in the embryo of Platynereis (Annelida). Rouxs Arch Dev Biol. 1993;202(5):270-5.

45. Costello DP. Experimental studies of germinal localization in nereis. I. The development of isolated blastomeres. J Exp Zool. 1945;100(1):19-66.

46. Lambert JD, Nagy LM. Asymmetric inheritance of centrosomally localized mRNAs during embryonic cleavages. Nature. 2002;420(6916):682-6.

47. Rabinowitz JS, Lambert JD. Spiralian quartet developmental potential is regulated by specific localization elements that mediate asymmetric RNA segregation. Development. 2010;137(23):4039-49.

48. Damen WGM, Vangrunsven LA, Vanloon AE. Transcriptional regulation of tubulin gene-expression in differentiating trochoblasts during early development of Patella vulgata. Development. 1994;120(10):2835-45.

49. Pfeifer K, Schaub C, Domsch K, Dorresteijn A, Wolfstetter G. Maternal inheritance of twist and analysis of MAPK activation in embryos of the polychaete annelid Platynereis dumerilii. PLoS One. 2014;9(5):e96702.

50. Schmerer MW, Null RW, Shankland M. Developmental transition to bilaterally symmetric cell divisions is regulated by Pax-mediated transcription in embryos of the leech Helobdella austinensis. Dev Biol. 2013; 382(1):149-59.

51. Chou HC, Pruitt MM, Bastin BR, Schneider SQ. A transcriptional blueprint for a spiral-cleaving embryo. BMC Genomics. 2016;17:552.

52. Chan XY, Lambert JD. Development of blastomere clones in the llyanassa embryo: transformation of the spiralian blastula into the larval body plan. Dev Genes Evol. 2014;224(3):159-74.

53. Amiel AR, Henry JQ, Seaver EC. An organizing activity is required for head patterning and cell fate specification in the polychaete annelid Capitella teleta: new insights into cell-cell signaling in Lophotrochozoa. Dev Biol. 2013;379(1):107-22.

54. Sweet HC. Specification of first quartet micromeres in Ilyanassa involves inherited factors and position with respect to the inducing D macromere. Development. 1998;125(20):4033-44.

55. Tosches MA, Arendt D. The bilaterian forebrain: an evolutionary chimaera. Curr Opin Neurobiol. 2013;23(6):1080-9.

56. Elshatory Y, Gan L. The LIM-homeobox gene Islet-1 is required for the development of restricted forebrain cholinergic neurons. J Neurosci. 2008; 28(13):3291-7

57. Posnien N, Koniszewski ND, Hein HJ, Bucher G. Candidate gene screen in the red flour beetle Tribolium reveals six 3 as ancient regulator of anterior 
median head and central complex development. PLoS Genet. 2011;7(12): e1002416.

58. Kahsai L, Winther AM. Chemical neuroanatomy of the Drosophila central complex: distribution of multiple neuropeptides in relation to neurotransmitters. J Comp Neurol. 2011;519(2):290-315

59. Nielsen C. Larval and adult brains. Evol Dev. 2005;7(5):483-9.

60. Lauri A, Brunet T, Handberg-Thorsager M, Fischer AH, Simakov O, Steinmetz PR, Tomer R, Keller PJ, Arendt D. Development of the annelid axochord: insights into notochord evolution. Science. 2014;345(6202):1365-8.

61. Benton MA, Akam M, Pavlopoulos A. Cell and tissue dynamics during Tribolium embryogenesis revealed by versatile fluorescence labeling approaches. Development. 2013;140(15):3210-20.

62. Conklin EG. The embryology of Crepidula. Boston: Ginn \& company; 1897.

63. Tessmar-Raible K, Steinmetz PR, Snyman H, Hassel M, Arendt D. Fluorescent two-color whole mount in situ hybridization in Platynereis dumerilii (Polychaeta, Annelida), an emerging marine molecular model for evolution and development. Biotechniques. 2005:39(4):460 462, 464.

64. Schneider SQ, Bowerman B. beta-Catenin asymmetries after all animal/ vegetal-oriented cell divisions in Platynereis dumerilii embryos mediate binary cell-fate specification. Dev Cell. 2007;13(1):73-86.

65. Denes AS, Jekely G, Steinmetz PR, Raible F, Snyman H, Prud'homme B, Ferrier DE, Balavoine G, Arendt D. Molecular architecture of annelid nerve cord supports common origin of nervous system centralization in bilateria. Cell. 2007;129(2):277-88.

66. Arendt $\mathrm{D}$, Technau $\mathrm{U}$, Wittbrodt J. Evolution of the bilaterian larval foregut. Nature. 2001:409(6816):81-5.

67. Jekely G, Arendt D. Cellular resolution expression profiling using confocal detection of NBT/BCIP precipitate by reflection microscopy. BioTechniques. 2007;42(6):751-5.

\section{Publisher's Note}

Springer Nature remains neutral with regard to jurisdictional claims in published maps and institutional affiliations.

Ready to submit your research? Choose BMC and benefit from:

- fast, convenient online submission

- thorough peer review by experienced researchers in your field

- rapid publication on acceptance

- support for research data, including large and complex data types

- gold Open Access which fosters wider collaboration and increased citations

- maximum visibility for your research: over $100 \mathrm{M}$ website views per year

At $\mathrm{BMC}$, research is always in progress.

Learn more biomedcentral.com/submissions 